\title{
NEW EVIDENCE ON THE RISK OF REQUIRING LONG-TERM CARE
}

\author{
Leora Friedberg, Wenliang Hou, Wei Sun, Anthony Webb, and Zhenyu Li
}

CRR WP 2014-12

Released: November 2014

\author{
Center for Retirement Research at Boston College \\ Hovey House \\ 140 Commonwealth Ave \\ Chestnut Hill, MA 02467
}

Tel: 617-552-1762 Fax: 617-552-0191

http://crr.bc.edu

Leora Friedberg is an associate professor at the University of Virginia. Wenliang Hou is a research associate at the Center for Retirement Research at Boston College (CRR). Wei Sun is an assistant professor at the Renmin University of China. Anthony Webb is a senior research economist at the CRR. Zhenyu $\mathrm{Li}$ is a former research associate at the CRR. The research reported herein was pursuant to a grant from the National Institutes of Health (NIH). The findings and conclusions expressed are solely those of the authors and do not represent the views of NIH, the University of Virginia, the Renmin University of China, or Boston College. The authors thank Siying Liu of the University of Virginia for excellent research assistance and Jeffrey Brown and Eric Stallard for their comments.

(C) 2014, Leora Friedberg, Wenliang Hou, Wei Sun, Anthony Webb, and Zhenyu Li. All rights reserved. Short sections of text, not to exceed two paragraphs, may be quoted without explicit permission provided that full credit, including $₫$ notice, is given to the source. 


\begin{abstract}
About the Center for Retirement Research
The Center for Retirement Research at Boston College, part of a consortium that includes parallel centers at the University of Michigan and the National Bureau of Economic Research, was established in 1998 through a grant from the Social Security Administration. The Center's mission is to produce first-class research and forge a strong link between the academic community and decision-makers in the public and private sectors around an issue of critical importance to the nation's future. To achieve this mission, the Center sponsors a wide variety of research projects, transmits new findings to a broad audience, trains new scholars, and broadens access to valuable data sources.
\end{abstract}

Center for Retirement Research at Boston College

Hovey House

140 Commonwealth Ave

Chestnut Hill, MA 02467

Tel: 617-552-1762 Fax: 617-552-0191

http://crr.bc.edu

Affiliated Institutions:

The Brookings Institution

Massachusetts Institute of Technology

Syracuse University

Urban Institute 


\begin{abstract}
Long-term care is one of the major expenses faced by many older Americans. Yet, we have only limited information about the risk of needing long-term care and the expected duration of care. The expectations of needing to receive home health care, live in an assisted living facility or live in a nursing home are essential inputs into models of optimal post-retirement saving and long-term care insurance purchase. Previous research has used the Robinson (1996) transition matrix, based on National Long Term Care Survey (NLTCS) data for 1982-89. The Robinson model predicts that men and women aged 65 have a 27 and 44 percent chance, respectively, of ever needing nursing home care. Recent evidence suggests that those earlier estimates may be extremely misleading in important dimensions. Using Health and Retirement Study (HRS) data from 1992-2010, Hurd, Michaud, and Rohwedder (2013) estimate that men and women aged 50 have a 50 and 65 percent chance, respectively, of ever needing care. But, they also estimate shorter average durations of care, resulting, as we show, from a greater chance of returning to the community, conditional on admission. If nursing home care is a highprobability but relatively low-cost occurrence, models that treat it as a lower-probability, highcost occurrence may overstate the value of insurance.

We update and modify the Robinson model using more recent data from both the NLTCS and the HRS. We show that the low lifetime utilization rates and high conditional mean durations of stay in the Robinson model are artifacts of specific features of the statistical model that was fitted to the data. We also show that impairment and most use of care by age has declined and that the 2004 NLTCS and the 1996-2010 HRS yield similar cross-sectional patterns of care use. We revise and update the care transition model, and we show that use of the new transition matrix substantially reduces simulated values of willingness-to-pay in an optimal longterm care insurance model.
\end{abstract}




\section{Introduction}

Long-term care is one of the major expenses faced by many older Americans. Yet, we have only limited information about the risk of needing to receive home health care, live in an assisted living facility or live in a nursing home and the expected duration of care. Understanding expected long-term care costs is critical for several purposes: gaining a comprehensive understanding of Medicaid finances, since 29.5\% of Medicaid funding in 2012 went to long-term care costs; analyzing optimal saving behavior by households preparing for old age; and explaining the long-term care insurance puzzle, since the use of insurance to shield against the risk of long-term care costs is surprisingly low.

Previous research has used the Robinson (1996) transition model, which shows the likelihood of transitioning from healthy to impaired states and how that affects the use of care, as based on National Long Term Care Survey (NLTCS) data for 1982-89. The Robinson model has been used by insurance companies to price long-term care insurance and by regulators to assess applications for premium increases on blocks of business. It has also been used by academic researchers modeling the long-term care insurance purchase decision and post-retirement saving and dis-saving. Recent evidence suggests that those earlier estimates may be extremely misleading in important dimensions. Using data from the National Long Term Care Survey (NLTCS) and Health and Retirement Study (HRS), this paper produces new estimates of the likelihood of needing different types of care. We update and modify the Robinson (1996) care transition model to obtain estimates of the monthly probabilities by age and gender of transitioning among five care states, 1) healthy and not requiring care, 2) requiring home health care, 3) residence in an assisted living facility, 4) residence in a nursing home, and 5) deceased.

Although the Robinson model continues to be widely used, the data upon which it is based date from 1982-89 and are now almost 30 years old. New research by Hurd, Michaud, and Rohwedder (2013) uses data from the HRS, which has the advantages of both exit interviews with relatives of deceased participants and an extremely long panel. Their analysis indicates that the Robinson model as originally specified may substantially underestimate the probability of ever receiving care and correspondingly overestimate the mean duration of care conditional on admission - key differences in understanding the incidence of care costs. For example, the Robinson model predicts that men and women aged 65 have a 27 and 44 percent chance, respectively, of ever needing care. Hurd, Michaud, and Rohwedder estimate that men and 
women aged 50 have a 50 and 65 percent chance, respectively, of ever needing care substantially higher, even though they consider the population at a younger age. But, they also estimate shorter average durations of care, conditional on admission, resulting, as we show, from a higher probability of exiting care to the community.

Insurance companies and insurance regulators may be mainly concerned with the unconditional mean duration of care, which will affect claim costs. We show that the existing model remains adequate for this purpose, subject to using updated data. But, academic researchers modeling the long-term care insurance purchase decision will be equally interested in the distribution of costs. If entry to a nursing home is a high-probability but relatively shortduration (and so low-cost) occurrence, models that treat it as a lower-probability, high-cost occurrence may overstate the value of insurance. We investigate the extent to which the results about care use differ because of changes in care use over time and because of design features of the model that Robinson matched to care data. Then, we show that our new estimates affect the valuation of long-term care insurance.

We first describe the HRS and NLTCS datasets and how they report impairment and care use. We provide a detailed description of the construction and estimation of the Robinson (1996) model. We identify design features that result in the statistical model understating the risk of admission and correspondingly overstating the conditional mean duration of stay. We show that the incidence of nursing home care utilization in more recent NLTCS data from 2004 matches that in the HRS data, and conclude that the substantial differences in patterns of care utilization between those obtained from simulations based on the Robinson model and those reported by Hurd, Michaud, and Rohwedder (2013) reflect the above design features.

We compute a revised and updated care transition matrix based on impairment and care data from the 1982-2004 NLTCS and the 1998-2010 HRS. Our care transition probabilities are chosen to match a detailed set of sample statistics from our simulated data with sample statistics of the datasets. We show that simulations of lifetime care utilization based on our updated model differ substantially from those in the original model and closely match the utilization rates reported in Hurd, Michaud, and Rohwedder (2013). Lastly, we show that use of the revised transition probabilities in a model of optimal wealth decumulation substantially reduces estimates of willingness to pay for long-term care insurance. Medicaid crowd-out is thus an even 
stronger explanation for the low level of long-term care insurance coverage than previously thought.

The remainder of this paper is organized as follows. Section 1 summarizes previous research, focusing on the Robinson (1996) model and the work of Hurd, Michaud, and Rohwedder (2013). Section 2 compares the HRS and NLTCS data. Section 3 describes the Robinson (1996) model in detail. Section 4 explains how we modify it to obtain transition probabilities that generate simulated lifetime care histories whose moments match those in the HRS data. Section 5 presents results and Section 6 concludes.

\section{Previous research}

Previous studies of the incidence of nursing home utilization include Liang, $\mathrm{Tu}$, and Whitelaw (1985), Cohen, Tell, and Wallack (1986), Kemper and Murtaugh (1991), Arling Hagan and Buhang (1992), Dick, Garber and MaCurdy (1994), Robinson (1996), Spillman and Lubitz (2002), Kelly et.al. (2010), Hurd, Michaud, and Rohwedder (2013), and Fong, Shao, and Sherris (2013). The Robinson (1996) model differs from the other papers in that it yields not only estimates of the distribution of the length of lifetime care use, but also monthly care status transition probabilities. The financial risk posed by nursing home care is the risk of not merely being unable to pay the nursing home bills, but also of being discharged to the community shorn of one's wealth. The Robinson transition matrix enables researchers to model this latter risk and has been utilized in calculations by Brown and Finkelstein (2008) and Sun and Webb (2013) of optimal long-term care insurance purchase and post retirement wealth decumulation. ${ }^{1}{ }^{1}$ The ability to model transition probabilities at monthly intervals is particularly valuable because the HRS data show that many individuals experience multiple short nursing home stays that would not be captured in a model that estimated care transitions at annual intervals. The model is highly regarded; Brown and Finkelstein (2004) report that it "has a very strong pedigree,” being used by “insurance regulators, private insurance companies, state agencies, state agencies administering public long-term care benefit programs, and the Society of Actuaries LTC Valuation Methods Task Force.”

\footnotetext{
${ }^{1}$ The model can also be applied to other household financial decisions that may be affected by health and/or care status. Reichling and Smetters (2013) use Robinson (1996) estimates of health, as distinct from care status, transitions in an analysis of optimal annuity purchase.
} 
Table 1 summarizes key data sources and findings from each of the above papers. Prior to Hurd, Michaud and Rohwedder (2013), the estimates of the risk of ever requiring care clustered within a narrow range. For example, using the Robinson (1996) model, Brown and Finkelstein (2008) simulate that men and women aged 65 face a 27 and 44 percent risk of requiring nursing home care, respectively. The most widely cited papers are Kemper and Murtaugh (1991) and Dick, Garber and MaCurdy (1994). Kemper and Murtaugh estimate similarly that 33 percent of men and 52 percent of women turning 65 in 1990 will ever require nursing home care. A puzzling feature of Dick, Garber, and MaCurdy (1994) is that, in contrast to the finding in all the other studies that women are at much higher risk, their results suggest that men and women are almost equally likely to ever need care, at 36 and 35 percent. ${ }^{2}$ Unlike the other papers, Fong, Shao, and Sherris (2013) focus on transitions between being nondisabled, functionally disabled, and dead, and do not distinguish between requiring home health and nursing home care. Using HRS data, they estimate the lifetime incidence of disability at age 65 and over at 37 percent for men and 54 percent for women.

Using the HRS, Hurd, Michaud, and Rohwedder (2013) report both parametric and nonparametric estimates of care utilization. Their parametric estimates of the probability of ever requiring care, conditional on attaining age 50, are 50 and 65 percent for men and women, respectively, much higher than previous estimates that were conditional on attaining age 65 . $^{3}$ Their non-parametric estimate is very similar, at 53 percent for men and women combined.

Meanwhile, Hurd, Michaud, and Rohwedder obtain much lower estimates of the mean duration of care, conditional on entry, so their estimates of unconditional mean durations of care are actually similar to those obtained previously. For example, the unconditional mean durations of care are 0.35 and 0.88 years for men and women respectively in Robinson and 0.48 and 0.73 years in Dick, Garber and MaCurdy, compared with 0.35 and 0.78 years respectively for the parameteric estimate in Hurd. Michaud, and Rohwedder.

Hurd, Michaud, and Rohwedder discuss potential explanations for their much higher rate of nursing home utilization. One explanation that they can easily reject is that there has been a

\footnotetext{
2 The probabilities of entering care can be computed by comparing the conditional with the unconditional mean durations of stay.

${ }^{3}$ Our analysis of the HRS data shows that individuals who die before age 65 are less likely to use nursing home care than those who die after age 65 and that few of those who do not use care after age 65 use care between age 50 and 64. So the probability of using care conditional on attaining age 50 is likely lower than the probability conditional on attaining age 65.
} 
dramatic increase in care utilization over the last 20 years. They show that there has been little overall trend in the prevalence of nursing home use in the HRS over the past 12 years, while our analyses of NLTCS data, discussed later, show that age-specific institutionalization rates have trended down over the longer term. A second possible explanation is that the HRS exit interviews provide an accurate picture of nursing home use in the last two years of life, in contrast to some other studies that either lack or have possibly lower-quality exit interviews. ${ }^{4}$ But, the omission of exit data does not appear to explain the much lower percentage using nursing homes in Dick, Garber, and MaCurdy. They use NLTCS data for 1982-84, and the 1984 NLTCS exit interviews ask almost identical questions to those in the HRS and use an almost identical recall period. Furthermore, as mentioned above, Dick, Garber, and MaCurdy report almost identical unconditional mean durations of stay to those in Hurd, Michaud, and Rohwedder, suggesting that they are doing a good job of capturing stays in the last years of life. Recall bias might explain the low utilization rates in Kemper and Murtaugh (1991), which are based on the 1986 Mortality Followback Survey in which respondents are asked about lifetime care use of deceased relatives. This survey will understate lifetime use to the extent that the respondent is either unaware of or does not recall stays. But, mean durations of stay in this study are also close to those in Hurd, Michaud, and Rohwedder (2013), casting doubt on this hypothesis. A third explanation proposed by Hurd, Michaud, and Rohwedder is that the methodology used by Dick, Garber, and MaCurdy to combine the NLTCS surveys results in a sample that is unrepresentative of the population.

The focus of this paper is on the Robinson (1996) model. As we will show in Section 3, a fourth explanation which we propose accounts for the differences between the Robinson and the Hurd, Michaud, and Rohwedder estimates. We argue that the Robinson model suffers from design features that result in it overstating the conditional mean duration of stay and understating the probability of entry. Specifically, the mechanism used to assign individuals to care does not allow for sufficient churn, so that most individuals either enter care and remain there until death or never enter care.

\footnotetext{
4 An example of the importance of exit data is apparent when considering the estimates of the lifetime risk of functional disability in Fong, Shao, and Sherritt (2013). As almost all nursing home residents are functionally disabled, but some functionally disabled individuals live in the community, the lifetime risk functional disability should be higher than the Hurd, Michaud, and Rohwedder (2013) estimates of the lifetime risk of entry to a nursing home. We hypothesize that the omission of exit data explains why the estimates are somewhat lower.
} 
While the disparity between the Robinson and the Hurd, Michaud, and Rohwedder estimates could arise because of an increase in the utilization of long-term care, as we mentioned earlier, in fact it is more likely that Robinson's data from 1982-89 overstates the current incidence of institutionalization. Manton and Gu (2001) and Manton, Gu, and Lamb (2006) show that the prevalence of chronic disability in the NLTCS has declined in recent years. The supply of assisted living facilities has also increased, and these may substitute for nursing home care. Although Hurd, Michaud, and Rohwedder (2013) find little trend in long-term care utilization from 1996 onwards, Manton, Gu, and Lamb (2006) show a near halving of institutionalization rates from 1982 to 2004.

Therefore, we endeavor to use more recent data, combining information from both the NLTCS and the HRS when updating the Robinson model. We continue to use the NLTCS dataset supplemented with the 1999 and 2004 waves to estimate health status transitions, one of the key ingredients to the care transition model, rather than to start afresh with the HRS. Our decision was motivated by three considerations. First, by continuing to use the NLTCS, we can show to what extent the changes in health status transitions reflect changes in the underlying data rather than the survey method. Second, the NLTCS data permit a more nuanced understanding of individuals' ability to perform activities of daily living (ADLs). This may be of particular value to insurance companies whose policy conditions may specify the required frequency or severity of the inability to perform an ADL. Third, although it is possible to infer use of assisted living facilities from the HRS, the 2004 NLTCS asks specifically about assisted living facilities, permitting a more accurate categorization. Meanwhile, we use the HRS to characterize patterns of lifetime utilization of nursing homes because it offers a long panel, detailed questions on separate care episodes, and exit interviews that report care in the final months of life.

A final point about the previous literature affects our use of the care transition matrix to compute willingness-to-pay for long-term care insurance. Neither Robinson (1996) nor the other papers cited above distinguish between Medicare and non-Medicare care. Although Medicare only pays for a maximum of 100 days care in a skilled nursing facility and then only after a qualifying hospital stay, it is the primary payer, and periods of institutionalization that are paid for by Medicare may have few adverse financial consequences for the household. We will account for this distinction because calculations of willingness to pay for long-term care insurance that fail to distinguish between Medicare and non-Medicare care, such as those of 
Brown and Finkelstein (2008) and Sun and Webb (2013), will overstate its value. The extent of the overstatement could be material, as 25.2 percent of all nursing home costs in 2011 were paid for by Medicare. ${ }^{5}$

\section{Data}

In this section we discuss how we make use of data from the HRS and the NLTCS. We use the NLTCS to estimate a transition matrix in health states that affect the need for care and then match predicted care states as a function of health to care states observed in the HRS and NLTCS. As we noted earlier, the NLTCS offers advantages for modeling health as people age, while the HRS offers more information about nursing home care for a long panel.

The Health and Retirement Study

We use the HRS to examine nursing home use for a panel of representative older Americans. Because the HRS has been operating for about twenty years, it still does not reveal entire care histories at older ages, and it begins with a non-institutionalized population. We deal with censored observations by linking together people in different cohorts to impute care histories; the key assumption is that health influences care in the same way for each cohort. Although the HRS reports the use of multiple types of care, it does not report detailed enough information to observe monthly care transitions, which is our goal. Rather, we estimate monthly health transition probabilities using NLTCS data and then simulate monthly care transition probabilities, conditional on simulated so that numerous simulated care statistics match those observed in the HRS and NLTCS. In this section we show these statistics about the incidence of nursing home use and how they relate to predicted nursing home use from the Robinson model.

The Health and Retirement Study (HRS) is a nationally representative panel survey of older Americans. The original HRS sample has been interviewed every two years since 1992 and comprises individuals aged approximately 51-61 (specifically, born between 1931 and 1941) and their spouses of any age. These participants report information about their use of multiple types of care and continue to be interviewed after they entered nursing homes; exit interviews are conducted with the relatives of deceased participants. In 1993, individuals aged 70 and over (born before 1924), called the AHEAD sample, joined the survey and were re-interviewed in

\footnotetext{
${ }^{5}$ Centers for Medicare and Medicaid Services (2013) Table 13.
} 
1995, 1998, and every two years thereafter. ${ }^{6}$ In practice, the age range of the sample is wider because spouses of age-eligible participants are interviewed, irrespective of age.

At baseline, only non-institutionalized individuals are included in the survey, so it is not representative of the entire elderly population. Hurd, Michaud, and Rohwedder (2013) show that by the third wave after entry, institutionalization rates by age are at the same level as in subsequent waves for cohorts who entered the survey at younger ages, presumably because those who were institutionalized at baseline and who were therefore excluded from the survey have mostly died. They infer that by then the sample is representative of the population. We follow them by dropping the first two interviews for each entering cohort. We also follow them by assigning the last non-zero weight given to respondents who were institutionalized, as the HRS assigns them a zero survey weight for aggregation purposes.

Most of the 1931-41 cohort, who were 51-61 in their first interview in 1992, were still alive at the 2010 interview, when they were aged 69-79. Those born before 1924, who were 70 in their first interview in 1993, are mostly deceased by 2010. So, we as yet lack a representative sample of individuals with nursing home utilization histories from 65 until death. Hurd, Michaud, and Rohwedder address these left- and right- censoring problems, arising because the past care utilization of participants who joined the panel after age 65 and because the future care utilization of participants who joined the panel at younger ages and have not yet died are unobserved. They begin by focusing on the cohort aged 70-74 in 1993; those who are still alive in 2010 are aged 87-91. They calculate the percentage of this cohort who died by 2010 and the percentages among the deceased and the survivors who utilized care between 1993 and 2010. To fill in the late-life care histories after ages 87-91, they then focus on the cohort aged 87-91 in 1993 and who had almost all died by 2010, and they similarly calculate the percentage who made use of care between 1993 and 2010. Assuming that the probability of using care after ages 87-91 is uncorrelated with the probability of using care between 70-74 and 87-91 and that the relationship between health status and care needs has not changed, they estimate the lifetime probability of using care conditional on surviving to ages 70-74 by multiplying out the above probabilities. By 2010, 33 percent of those aged 70-74 in 1993 were still alive. Between 1993 and 2010, 29 percent of survivors and 49 percent of the deceased ever used care. Among those

\footnotetext{
${ }^{6}$ Those born 1925-30 and 1942-47 were added in 1998, and younger individuals were added in 2004 and 2010. These cohorts have not been observed for as long a period after entering the HRS and hence are not used for our analysis.
} 
aged 87-91 in 1993, 65 percent ever used care. The probability of using care after age 70-74 thus equals $(0.67 * 0.49)+(0.33 *(0.29+(0.71 * 0.65)))$, or 57.6 percent - substantially higher than the rates from Robinson (1996). Hurd, Michaud, and Rohwedder undertake a similar analysis from ages 50-54 to 70-74 to arrive at an overall probability of using care after age 50-54 of 53.6 percent.

A potential concern with the Hurd, Michaud, and Rohwedder approach is that the probability of entering care may be positively or negatively correlated with prior episodes of institutionalization. ${ }^{7}$ We account for this possible correlation by taking advantage of the repeated waves of the HRS to splice together individuals with similar nursing home use across ages in order to impute complete nursing home use histories that incorporate correlations across care episodes. Because we do not observe any single age cohort for longer than 1992-2010, we must combine information from different age cohorts to yield histories from age 65 until the age of death. Our starting point, as in Hurd, Michaud, and Rohwedder, is AHEAD individuals born between 1919-1923 and aged 75-79 in 1998 (recall that we drop individuals in the first two waves because the sample begins with only those who are not institutionalized) who, if they survived to 2010, were then aged 87-91. We use multiple hot-deck imputation, as in Rubin (1987), to splice them with HRS individuals born in 1931-1935, who were turning 65 between 1996 and 2000 (when we first observed them) and who were 75-79 in 2010. We also splice HRS survivors with AHEAD participants born between 1907-1911, who were aged 87-91 in 1998 and, had they survived, would have been age 99-103 in 2010, in order to impute care histories at ages beyond $87-91 .^{8}$ Only 19 AHEAD participants attained those ages in 2010, so this procedure yields an essentially complete history from age 65. Our multiple hot-decks use age, gender, number of ADL limitations, marital status, and current nursing home status in order to splice together people with similar characteristics. Finally, we add to the sample individuals who were observed at age 65 but died by ages $75-79 .{ }^{9}$

\footnotetext{
${ }^{7}$ If it is positively correlated, their approach will overstate lifetime risk for the average individual because many observed spells will be repeat spells for a relatively small number of individuals. Conversely, if it is negatively correlated, it will understate lifetime risk, because not having experienced a spell will raise one's future risk of a spell.

${ }^{8}$ Our care utilization rates are therefore representative of the period from 1998 onwards, rather than of any particular birth cohort.

${ }^{9}$ We ensure that the weighted number added accords with the predictions of Social Security Administration mortality tables for the relevant birth cohorts.
} 
At every interview, participants, or in the case of exit interviews, relatives of deceased participants, were asked whether they had a nursing home stay, the number of stays and the number of nights spent in a nursing home subsequent to the previous interview, and whether they were living in a nursing home at the date of the interview or died (asked only in exit interviews) while in a nursing home. Table 2 compares sample statistics derived from our spliced HRS lifetime nursing home utilization histories with sample statistics from the Robinson (1996) model reported in Brown and Finkelstein (2004) and based on the earlier NLTCS. Our unconditional mean durations of care are similar to those of Robinson. ${ }^{10}$ But, our probabilities of entering a nursing home are much higher than those of Robinson, and our conditional mean durations of care correspondingly lower. We calculate that men and women have a 2 percent and 7 percent chance of spending more than five years in care, compared with 5 and 12 percent in the Robinson model. Our probabilities of entering care, conditional on attaining age 65, are 44 and 58 percent for men and women. Our overall average of 51 percent is slightly lower than the Hurd, Michaud, and Rohwedder non-parametric estimate of 53 percent. ${ }^{11}$ We estimate slightly higher conditional means for both men (0.85 vs. 0.76 years), and women (1.37 vs. 1.20 years).

Hurd, Michaud, and Rohwedder focus solely on the utilization of nursing home care. The HRS contains limited information about home health care, which we are unable to use in the estimation, and hence we will follow Robinson in using NLTCS information on usage of home health care. $^{12}$ We also follow Robinson in using NLTCS information on assisted living, and we compare it to HRS information ${ }^{13}$

\footnotetext{
${ }^{10}$ Brown and Finkelstein (2007) use the Robinson model to estimate sales loads on long-term care insurance policies of 0.50 and -0.06 for men and women, respectively, where load is defined as 1-(expected present value of benefits/expected present value of premiums). There is a close bit not exact relationship between loads and unconditional mean durations of stay, and it follows that as the HRS are close to the Robinson unconditional means, the Brown and Finkelstein (2007) estimates remain valid, subject to any adjustments required to reflect changes in premiums.

${ }^{11}$ We were able to precisely replicate their mortality and nursing home utilization rates for the period 1993-2010 individuals aged 70-74 in 1993.

${ }^{12}$ The RAND version of the dataset, which contains a subset of cleaned and imputed variables, reports responses to a single question, namely whether any medically trained person had come to the respondent's home during the past two years to provide help. We clean and impute the exit data, which has the same question for HRS respondents who have died. Reliance on this question may, however, fail to capture care provided by home health aides who are not medically trained and fails to measure the duration or intensity of care. An alternative approach would be to rely on questions in the original dataset asking whether individuals ever received assistance performing ADLs. The disadvantage with this approach is that individuals are not asked to specify the frequency of the assistance, nor whether it was provided by family members or by paid caregivers.

${ }^{13}$ Assisted living options include the Independent Living Community (ILC), Assisted living Residence (ALR), and Continuing Care Retirement Community (CCRC). Coe and Boyle (2012) explain their distinguishing features. All three types offer meals, but only CCRCs and ALRs offer assistance with performing ADLs, and only CCRCs offer
} 
Table 3A reports the living arrangements by age and gender of a pooled cross section of HRS participants, drawn from the 1996 to 2010 waves. We report the percentages living in a nursing home at the time of the interview, using a nursing home since the previous interview, living in an assisted living facility at the time of interview or immediately before in the case of deceased participants, and using home health care by someone medically trained since the previous interview, and the mean number of stays and number of nights in a nursing home since the previous interview, conditional on any use. ${ }^{14}$ Care of all types rises by age, with an early rise in home health care use that is surpassed by nursing home use at very old ages. For example, at ages 75-79 13.2 percent of men and 14.2 percent of women have used home health care in the last two years, while 6.9 percent of men and 8.6 percent of women have used a nursing home; these rates are almost even, in the 20-30 percent range at ages 85-89, and at ages 90-94 nursing home use exceeds home health care use. Assisted living residence reaches the 5 percent range for people in their late 80s and then declines at very old ages. The percentages living in a nursing home are virtually identical to those reported in Hurd, Michaud, and Rohwedder. ${ }^{15}$ Table 3B report the same data, restricted to the 2004 wave, which facilitates comparison with the NLTCS data discussed next.

\section{The National Long-Term Care Survey}

We use the NLTCS to estimate a transition matrix in health states, defined by physical and cognitive impairment, that affect the need for care. We will then match care states as predicted by the need for care to care states observed in the HRS and NLTCS. We use nursing home data from the HRS and assisted living and home health care data from the NLTCS. In this

nursing care. ALRs are typically rented, but CCRCs may be either rented or owner-occupied. The HRS first asks participants whether they are living in a nursing home. If they are not, the financial respondent answers the housing questionnaire. This does not directly ask about the category of facility used, and the category must be inferred from responses to questions about care services offered. These enable us to determine whether participants are living in an ILC, which does not offer nursing care, as distinct from an ALR or a CCRC. We classify as assisted living an accommodation that has the characteristics of either an ALR or a CCRC. In contrast, the NLTCS asks questions that enable us to directly identify residents of ALRs and CCRCs. We therefore use NLTCS data to construct our transition matrix.

${ }^{14}$ Some categories, for example, living in a nursing home and in an assisted living facility at the time of interview, are mutually exclusive. But others, for example, using a nursing home and using home health care since the previous interview, are not.

${ }^{15}$ Table 2 of Hurd, Michaud, and Rohwedder (2013) that 2.4 percent of participants were living in a nursing home at the time of interview, and 4.5 percent reported nursing home utilization in the past two years. These calculations exclude exit interviews and do not impose any age restriction. Our corresponding analysis, also excluding exit interviews, yields 2.37 and 4.50 percent. Our sample sizes differ slightly, possibly reflecting differences in the application of sample weights. 
section, we discuss how we use the NLTCS data on health and on care and compare statistics from the 1984 NLTCS, 2004 NLTCS, and HRS.

The National Long-Term Care Survey is a nationally representative survey of Medicare beneficiaries aged 65 or over. It is a panel survey that interviewed participants in 1982, 1984, 1989, 1999, and 2004. At each wave, a screener questionnaire is used to divide the sample into the non-disabled, the disabled who live in the community, and the disabled who live in an institution. Those who are non-disabled are asked no further questions in that wave. Those who are disabled and live in the community are administered a community survey. In the first wave, no further questions are asked of those who are institutionalized, but in subsequent waves, they are administered a survey for institutionalized individuals. The NLTCS takes steps to maintain a representative sample and also obtain information about the deceased. The 1982 survey began with 20,485 individuals. About 5,000 people die between waves and are replaced by a sample of about that size who attained age 65 subsequent to the previous wave. ${ }^{16}$ Not all the prior nondisabled are interviewed in the following wave, and the sampling fraction of prior non-disabled is adjusted to oversample those who are aged over 75. In 1984, the NLTCS interviewed the relatives of participants who had died between 1982 and 1984, and subsequent to 1999, the NLTCS also interviewed the relatives of a subsample of 544 individuals drawn from participants who were alive in 1999, but died between 1999 and 2001.

The Robinson (1996) model focuses as a first step on health, as determined by physical and cognitive impairment and then on care status, conditional on health. This reflects the goal of the model, which is to serve as a pricing tool for insurance company actuaries and regulators. Policy benefits are triggered by need for care as defined by ADL status, and insurance companies anticipate that almost all eligible individuals will claim benefits. Therefore, Robinson characterizes the need for care in terms of both cognitive impairment as reported directly and physical impairment as captured by need for assistance with Activities of Daily Living (ADLs) and Instrumental Activities of Daily Living (IADLs). Following Robinson, we model transitions among seven states of worsening health, but based on our analysis and comparisons across data sets, we modify how ADLs and IADLs are used to define poor health.

\footnotetext{
${ }^{16}$ Between 1982-84, about 3200 died and then 4900 joined the survey in 1984. Between 1984-89, about 6200 died and then 4900 joined the survey in 1989. Between 1989-94, about 5700 died and then 5000 joined in 1994.
} 
The NLTCS asks detailed questions about cognitive and physical impairment. Robinson categorizes an individual as suffering from a cognitive impairment if he is unable to provide correct answers to five or more out of a total of ten questions that are designed to measure cognitive functioning. Physical impairment is measured by ADL and IADL limitations. The ADLs comprise eating, bathing, dressing, toileting, being able to get out of bed, and bowel and bladder management. Defining disability involves determining thresholds for ADL limitations, depending on capacities that people report, and also deciding how to assign disability rates to those who are screened out in later sub-sampling after providing particular answers about ADLs. Previous authors have taken various approaches, which we compare in detail in the Appendix and which yield differing trends in disability. For example, we show that Robinson's definitions result in both a high and increasing number of individuals experiencing limitations with IADLs, which seems unrealistic, while other definitions result in substantial declines in ADLs over time. In estimating the health transition matrix, we will include time trends that are allowed to differ for some broad categories of health transitions to account for changes in impairment over time. Besides that, the other major adjustment we make to Robinson's approach is to broaden the definition of disability so that more people are classified as experiencing limitations with ADLs, in agreement with other authors, and fewer with IADLs; we still use a narrower definition than some other authors because our goal is to model disability that triggers long-term care insurance benefits.

After settling on a definition of IADL and ADL limitations, we follow Robinson in defining states of progressively greater impairment: well (no cognitive impairment and able to perform all ADLs and IADLs; unable to perform 1+ IADL but able to perform ADLs; no cognitive impairment but unable to perform 1, 2, or 3+ ADLs; or cognitive impairment and unable to perform $<2$ or $2+$ ADLs. Table 4 A reports the percentages of NLTCS participants in each of these seven impairment states, by age group, in 1984 and 2004, using our preferred definitions. Consistent with previous research, age-specific disability rates and thus eligibility to claim home health care insurance benefits declined over the above period. For example, the share of the sample who are well (no IADL or ADL limitations) is 54.2\% for men aged 85-89 in 1984 and $65.4 \%$ in 2004.

Recall that we use the NLTCS to generate statistics on assisted living and home health care. Our use of these questions is described in the Appendix. Table 4B reports the incidence of 
home health care utilization and residence in nursing homes and assisted living facilities, by age, in the above years. The age-specific incidence of nursing home utilization declined in a similar fashion as impairment declined. In 1984, 4.1 percent of men and 8.8 percent of women over 65 lived in nursing homes, compared with 2.4 and 5.2 percent in 2004, declines of 40 percent. The 2004 numbers aggregate to 1.21 million, somewhat lower than the 1.32 million reported in Table 6 of the U.S. Department of Health and Human Services (2009), based on National Nursing Home Survey data for the same year. In results that are not reported, we find that the percentages living in assisted living facilities by age increased from 1984 to 1999 and then declined in 2004, possibly reflecting the more precise wording of the relevant questions in 2004.

\section{How similar are the two surveys?}

One of our goals is to use updated data on care needs, and with two possible data sources, we can compare care outcomes at the same date. Excluding the HRS exit interviews, the utilization of nursing homes and assisted living facilities in the 2004 HRS is very similar to that in the 2004 NLTCS (Table 4B), which increases our confidence when we combine information from both in order to update the Robinson model. ${ }^{17}$ In the HRS 2.4 percent of men and 4.9 percent of women were living in a nursing home at the time of the interview, compared with 2.4 and 5.2 percent of NLTCS participants. It is not possible to make a comparison of the number of separate episodes of institutionalization because of differences in the structure of the questions. ${ }^{18}$ It is also not possible to make a similar comparison of rates of home health care utilization because the HRS asks about any care utilization in the last two years whereas the NLTCS asks about care utilization in the last month, so the rate of home health care utilization is higher in the HRS.

\footnotetext{
${ }^{17}$ HRS analyses, similar to Tables 3A and B, but excluding exit interviews, are available from the authors on request.

${ }^{18}$ The NLTCS comprises three surveys - of institutionalized individuals, of disabled individuals living in the community, and an interview designed to screen out the non-disabled. Institutionalized individuals are asked how many times they were admitted to a nursing home in the last four years and the dates of the last four admissions. Disabled and non-disabled non-institutionalized individuals are asked how many times they have ever been a patient in a nursing home, and the dates and durations of the last two admissions. In 1999, the relatives of some deceased individuals are asked whether they died in a nursing home, and if so, when they were admitted and how long they stayed in the nursing home. They are also asked about the dates and durations of prior institutionalizations. The lack of data on the durations of periods of institutionalization of individuals who were institutionalized in 1999 means that it is not possible to calculate the number of nights stay over any period.
} 


\section{The Robinson Model}

Robinson (1996) published a widely used transition matrix indicating the likelihood of moving among care states. The Robinson model has two parts. The first part uses two adjacent waves of the NLTCS to generate transitions in health and then fits a likelihood model that estimates monthly health transition probabilities that fit the data moments. The second part uses the health transition probabilities to estimate care status transition probabilities. We first describe Robinson's health transition model and then the care model. Finally, we describe our alternative approach to modeling care status transition probabilities, conditional on health transitions. Our major changes focus on nursing home entry and exit; we match considerably more statistics characterizing the distribution of nursing home care, and this allows our simulated data to match the degree of churn observed in nursing home use in the HRS.

Robinson omits, as do we, possible behavioral factors that influence the demand for care, independently of impairment. For example, we do not include marital status or the proximity of adult children; while these affect the arrangement of care-giving, as shown by Byrne et. al. (2009), Hiedemann et. al. (2013), or Pezzin and Schone (1999), they are not used to determine claims for long-term care insurance policies. Also, Costa Font and Courbage (2014) show that the availability of informal care may be complementary with purchases of long-term care insurance by households who care about the quality of life of their potential care-givers. Meanwhile, the empirical importance of available family members may reflect at least in part the impact of socioeconomic status on care and not solely the impact of family structure, but modeling this relationship, as in the papers just cited, is considerably more complicated, especially with limited data from the NLTCS on socioeconomic status.

\section{The health transition model}

The first step is to use our definitions from above to classify NLTCS individuals into one of eight health states: 1) well, 2) able to perform activities of daily living (ADLs) but unable to perform one or more instrumental activity of daily living (IADL), 3) not cognitively impaired but unable to perform one ADL, 4) not cognitively impaired but unable to perform two ADLs, 5) not cognitively impaired but unable to perform three or more ADLs, 6), cognitively impaired and unable to perform zero or one ADLs 7) cognitively impaired and unable to perform two or more 
ADLs, and 8) dead. ${ }^{19}$ The second step is to cross-tabulate health states in each pair of adjacent waves (1982-84, 1984-89, and so on) to generate health transitions by age group (65-74, 75-84, and 85 plus) and gender, a total of six categories. ${ }^{20}$

We use maximum likelihood to estimate health transition probabilities as a function of age, gender, and year for each of the six categories, with each matrix containing a total of 56 probabilities. The model takes the following form:

$$
r_{i, j}(s, x, y)=\exp \left[a_{i, j}+b_{k \in\{i j\}}(s-0.5)+c_{k \in\{i j j} \frac{x-80}{100}+d_{k \in\{i j j}(y-1982)+\varepsilon_{i j j}\right]_{(1)}
$$

where $r_{i j}(s, x, y)$ is the annual rate of transition from status $i$ to status $j$ for an individual aged $x$ of gender $s$ in year $y$. No constraints are placed on the 49 values of $\boldsymbol{a}_{\ddot{\ddot{y}}}$, the likelihood of a transition for the base case. ${ }^{21}$ We constrain the other parameter values to be the same for broad types of health transitions in order to reduce dimensionality. The gender adjustment parameter $b_{k \in\{i, j\}}$ values are constrained to three values, one value for $k$ such that $i>j$, recovery to a better health status; one for $j=8$, death; and one for other combinations of $i$ and $j$ that involve equal or worse health but not death. These adjustment parameters allow the baseline probability to differ for men and women when considering improvements compared to deterioration and when considering mortality. The age slope parameters $c_{k}$, are constrained to five values including the three for the gender adjustment as well as separate values for males and females when $i=1$ (well). ${ }^{22}$

A drawback is that we cannot allow for unrestricted changes over time in health transitions. Ideally, we would estimate the model separately for each year, allowing all the $a_{\bar{y}}$,

\footnotetext{
${ }^{19}$ The detailed classification is to assist insurance companies in pricing long-term care insurance. Some policies place ADLs in five categories, paying benefits if individuals are unable to perform one or more ADL. Others place ADLs in six categories and pay benefits if the individual is unable to perform two or more ADLs

${ }^{20}$ As previously mentioned, the NLTCS is designed to oversample institutionalized individuals. We adjust for this by constructing transition weights. We obtain NLTCS mortality data that permit us to identify each participant's vital status and date of death. We adjust the cross section weights to reflect the possibility that an individual who was alive at both time $t$ and $t+5$ may not be interviewed at time $t+5$, whereas all deceased individuals will be included in the $t+5$ sample.

${ }^{21}$ The $a_{i j}$ terms are estimated for transitions to states $i \neq j$, so there are terms for the transitions from the seven initial states to seven different terminal states, yielding 49.

${ }^{22}$ We follow Robinson in assuming that the 1984 survey was administered exactly two years after the 1982 survey and that the 1989 and subsequent surveys were administered at five-year intervals. The actual interval between the 1982 and 1984 surveys varied from one year ten months to two years and two months.
} 
$\boldsymbol{b}_{\vec{j}}$, and $\boldsymbol{c}_{i j}$ coefficients to vary over time. ${ }^{23}$ We find that the estimated parameter values are unstable, and instead we include a $d_{k}$ linear time trend, the slope of which is allowed to differ for mortality, improving health, and all other transitions, as for the $b_{k}$ terms. The time trend has an important effect. Our health care status simulation shows that, based on 1984 transition probabilities, $11.6 \%$ of men aged 65 would be healthy at age 85 , and $78.7 \%$ would be dead at age 85. Based on 2004 transition probabilities, 15.3\% would be healthy and $75.0 \%$ dead, so in more recent waves, the probability of being in good health is higher and the probability of death is lower. $^{24}$

\section{The Robinson care status transition model}

While we largely follow Robinson in modeling health transitions, we have identified problems in the statistical model of the relationship between health transitions and care transitions which lead to misleading estimates of conditional mean durations in care. To translate health transitions into care transitions, Robinson first simulates a large number of month-by-month health status histories. By construction, the percentages of individuals in each health status at each age match those observed in the underlying data. Then, he models use of different types of care in stages, beginning with nursing home care.

The second step is to estimate the probability of being in a nursing home, given age, gender, and health status. Robinson accomplishes this by estimating a logistic model based on 1984 and 1989 data. ${ }^{25}$ Age is classified as 65-74, 75-84, and 85 plus, and health status takes six possible values, along with well and deceased. So, two waves of data yield a total of 72 observations of nursing home utilization by age, gender, impairment state, and year. ${ }^{26}$ The third step is to assign nursing home status to each simulated individual each month, given age, gender, and health status. Robinson draws a number from the uniform $[0,1]$ distribution for each

\footnotetext{
${ }^{23}$ The NLTCS enables researchers to identify health status at the date of the interview. It does not permit researchers to identify when the individual's health status changed, or whether the individual transitioned through other health states between the interviews. The MLE procedure yields health status transition probabilities that best fit the pattern of transitions from one interview date to the next.

${ }^{24}$ The transition probabilities, when applied to 1999 NLTCS data, yield weighted five-year mortality rates that are almost identical to those observed in the data. We conclude that the high mortality rates reflect the data rather than any shortcomings in our model.

${ }^{25}$ Robinson makes several further modifications to his model, including smoothing some outcomes and making an adjustment to reduce the probability of requiring care, based on an analysis of 1994 NLTCS data.

${ }^{26}$ Robinson includes a dummy for the observation being drawn from 1984-89 vs. 1982-84.
} 
simulated individual, which serves as their permanent threshold. As long as this threshold exceeds the propensity computed for the individual's sex, attained age, and health status in the NLTCS, the individual is deemed to remain in the community. Once the individual's nursing home propensity increases to a level above his/her threshold (due to aging or worsening of health), the simulated individual is deemed to be institutionalized. If the individual's health status improves their prevalence rate may fall below the threshold, resulting in a simulated nursing home discharge to the community.

By matching simulated nursing home entry and discharge rates to a detailed set of sample statistics from the HRS, including some related to leaving care alive, we replicate the degree of "churning" in the data. Matching this churn is the key problem that we have identified in the Robinson model. As health status typically worsens with age, the Robinson model described above would return few individuals to the community. In practice, some individuals return, even if impairment does not lessen. For example, individuals may be institutionalized to provide respite for informal caregivers, or after a period of hospitalization. Robinson incorporates a duration adjustment factor that increases the probability of institutionalization after the onset of disability and reduces it for individuals who have remained in the same disability state for a long period of time. To illustrate, suppose an individual transitions from being disability-free to having one ADL, remains in that state for many months, and then dies. The probability of nursing home admission, given that ADL state, is 0.2. Assuming away an age effect, if the individual's draw from the uniform distribution is less than 0.2 , he is assumed to be admitted to care immediately on the onset of disability and to remain there until he dies. If the draw is greater than 0.2 , he never goes into care. If the admission probabilities are then adjusted in Robinson's model to 0.25 (say) for the first 12 months after the onset of a disability, and to 0.16 thereafter, an individual with a draw of 0.22 would be assumed to be institutionalized for 12 months and then discharged, generating some churning. But, these adjustment factors are adhoc. Based on the discrepancy with Hurd, Michaud, and Rohwedder , they yield an inadequate degree of churning, and our use of additional statistics representing durations as well as utilization rates addresses this. ${ }^{27}$

\footnotetext{
${ }^{27}$ Hurd, Michaud, and Rohwedder show that one will underestimate lifetime care utilization if one adds up all the episodes of care but omits the period from the final live interview to the date of death. The understatement will be particularly severe if, as in the case of the NLTCS, interviews take place at five-year intervals. This is not a particular concern for the Robinson model because it simulates health and care use histories right up to the date of
} 
The third step is to simulate the use of assisted living facilities. Robinson tabulates residence in assisted living facilities by gender, three age groups as above, and health. He makes some adjustments and interpolates over age to obtain probabilities of assisted living residence for every age. As above, he assigns an individual to an assisted living facility based on their draw from the random uniform distribution. Robinson relates the likelihood of entry into assisted living on the level of impairment; we model it as depending on a worsening of impairment.

The fourth step is to assign home health care. Robinson assumes that all individuals with ADL limitations receive home health care, although some such individuals in fact forgo paid care and depend instead on informal home health care from family members. Benefit payments on long-term care policies are conditional on ADL status, and this focus on benefit triggers reflects the original purpose of the model, namely to assist in pricing long-term care insurance.

\section{Our revised care status transition model}

We take a more systematic approach to relate impairment transitions to care status than does Robinson, who makes specific adjustments in order to replicate certain features of the data. We match simulated statistics to actual statistics, and we make use of recent care information from the HRS for nursing home information, which has a long panel and better exit information. Using our spliced panel of HRS participants for ages 65 onward, we follow Ameriks, Caplin, Laufer, and Van Nieuwerburgh (2011), who also analyze nursing home care data, in focusing on the following nursing home statistics:

- probability of ever using nursing home care

- average age of first use, conditional on use

- conditional mean number of years spent in care

- conditional probability of using for more than one, three, and five years

- $\quad$ percentage of nursing home entrants who return to the community

- $\quad$ percentage of nursing home entrants who have only one stay. ${ }^{28}$

Care statistics for the full sample appeared in Table 2, while we choose care transition probabilities to minimize the difference between simulated and HRS care statistics conditional on health and age.

death. Health is allowed to deteriorate with proximity to death, and as care usage depends on health status, the probability of using care will increase with proximity to death.

${ }^{28}$ This last statistic differs from Ameriks et al., who use the conditional mean number of spells. 
The first step in the calculation, similar to Robinson, is to simulate 10,000 health status histories, based on the estimated health transition matrix described above. The second step is to create a 4x5 care transition matrix for each age and for each of the 56 (7x8) health status transitions. There are four care states possible at time $t$ (in community, receiving home health care, in assisted living, in nursing home) and five care states at time $t+1$ (the four above and deceased), along with seven health states at time $t$ and eight health states at time $t+1$ (including deceased). In theory this would require us to estimate an unfeasibly large total of $56 * 4 * 5=1120$ age-varying probabilities. In reality, many of these transition probabilities are determinate. Consider, for example, an individual who transitions from the health state in which he has two ADLs to the health state in which he is dead. We require that the initial care states must be "home health care," “assisted living,” or “nursing home,” and cannot be “well” or “dead,” as this is implied by the definition of ADLs, and that the individual similarly transitions from these care states to care state “dead” with probability one. Other transitions can never occur. For example, an individual who is in health state "well" at time t can only be in care state "well". On the other hand, analysis of both HRS and NLTCS data reveals that some individuals are in a nursing home even though they report only having one ADL. ${ }^{29}$ While this may reflect errors in reporting ADL status, rather than attempting to correct ADL status we allow individuals with only one ADL to enter nursing homes. Overall, we need to estimate only 411 conditional transition probabilities. $^{30}$

Now, focusing on specific care states, the third step is to estimate probabilities of entering or remaining in a nursing home between time $t$ and $t+1$. We choose probabilities that minimize the distance between the statistics characterizing the distribution of nursing home care utilization in the HRS data and the corresponding statistics in simulated care histories. These simulated care histories are created by applying the care status transition probabilities to the simulated health status histories.

The probability of entering care is assumed to be zero when the individual is in health states 1 , 2, or 8 at $\mathrm{t}+1$, and greater than zero when in health states $3,4,5,6$, or 7 at $t+1$. The

\footnotetext{
${ }^{29}$ As mentioned previously, the ADL questions in the HRS are less detailed than those in the NLTCS. We assigned predicted probabilities of cognitive impairment using a dataset available on the HRS website, supplemented by predicted probabilities for other waves generously supplied to us by Michael Hurd of RAND. Few of the institutionalized individuals with only one ADL limitation appeared by be suffering from cognitive impairment. ${ }^{30}$ Of the 56 health status transitions, care status is pre-determined for 21. For the other 35, some of the 20 care transitions are not possible. In 10 cases there are 4 possible transitions, and in 25 cases there are 14 possible transitions.
} 
probability of entering a nursing home if not already in one is assumed to depend solely on age and on health status at times $t$ and $t+1$, not on care status at time $t .{ }^{31}$ We assume that the probability of entry to a nursing home equals

$$
\frac{1}{1+e^{-\left(\beta_{3} h_{3}+\beta_{4} h_{4}+\beta_{5} h_{5}+\beta_{6} h_{6}+\beta_{7} h_{7}+\beta_{8} A D L+\beta_{9} C I+\beta_{10} A G E-65\right)}}
$$

where $h_{3} h_{4} h_{5} h_{6} h_{7}$ indicate that the individual is in health states $3,4,5,6$, or 7 at time $t+1$, $A D L$ indicates that the individual had ADL limitations at time $t+1$ but had none at time $t, C I$ indicates that the individual began to suffer from a cognitive impairment at time $t+1$ after being unimpaired at time $t$, and $A G E$ indicates the individual's age in years at time $t$. It is impossible for us to allow a different coefficient for all possible health transitions, so instead we focus on decisive changes for the worse in health. Similarly, we impose the following constraints: $\beta_{5} \geq \beta_{4} \geq \beta_{3}$ (individuals with more ADL limitations are at least as likely to enter care), $\boldsymbol{\beta}_{7} \geq \boldsymbol{\beta}_{6}$ (conditional on having a cognitive impairment, individuals with 2 or more ADL limitations are at least as likely as individuals with 0-1 ADL limitations to enter care), $\boldsymbol{\beta}_{6} \geq \boldsymbol{\beta}_{3}$ (individuals with cognitive impairment and 0-1 ADL limitation are at least as likely as individuals with 1 ADL limitation and no cognitive impairment to enter care), and $\boldsymbol{\beta}_{\boldsymbol{7}} \geq \boldsymbol{\beta}_{\mathbf{4}}$ (individuals with cognitive impairment and at least 2 ADL limitations are at least as likely as individuals with 2 ADL limitations but no cognitive impairment to enter care). The model assumes that onset of disability may also precipitate entry, as governed by $\beta_{8}$ and $\beta_{9}$. ${ }^{32}$ The probability of exiting a nursing home is specified similarly, except that we omit the $\beta_{8}$ and $\beta_{9}$ terms.

We estimate the model using the method of simulated moments, as in the structural models of Gustman and Steinmeier (2005) and Ameriks et. al. (2011). The method finds the parameter values that minimize the weighted distance between the sample and the simulated moments. ${ }^{33}$ To scale the moments to the same units, we express all the differences between the simulated and HRS sample statistics in terms of percentage deviations from the relevant means.

\footnotetext{
${ }^{31}$ An alternative would be to assume that the probability of entering nursing home also depends on care status, as might be the case if home health care was a substitute for institutional care.

${ }^{32}$ Individual-level differences in propensity to enter care may produce a spike in entry immediately after onset of disability, with high propensity individuals entering immediately and low propensity individuals entering gradually over time.

${ }^{33}$ We use a grid search to estimate the betas, but estimating all the betas simultaneously using a fine grid exceeds the limits of even multi-core computers using parallel processing - the number of calculations equals the number of grid points to the power of the number of betas. We first use a coarse grid. Even so, it is not possible to estimate all the betas simultaneously, and we therefore initially constrain $\beta_{3}-\beta_{7}$ to take a single value, while allowing the
} 
The fourth step is to estimate transition probabilities between assisted living and other care states. We assume that individuals only exit from assisted living to nursing homes or death. We assign transition probabilities into assisted living from other care states and out of assisted living to nursing homes or death so that the percentages of individuals in assisted living facilities in five-year age ranges equals that observed in the 2004 NLTCS data, and we restrict transitions into assisted living to occur with a positive probability only upon the onset of two or more ADLs or cognitive impairment, for those who do not enter a nursing home. The fifth step is to assume that all individuals with two or more ADL limitations who are not in assisted living or nursing home care status are receiving home health care.

The above procedures yield transition probabilities that vary with health states at time $t$ and $t+1$, with age, and with gender. For some purposes, for example, calculating willingness to pay for long-term care insurance, transition probabilities that vary only with age and gender but not with impairment may be preferable because they eliminate a state variable. Therefore, our sixth and final step is to use our Monte-Carlo simulations to calculate unconditional transition probabilities. $^{34}$

\section{Results}

\section{The health transition matrix}

We begin by showing our parameter estimates for the health transition model in equation (2), which we estimated using maximum likelihood. The parameters for the impairment transition model in Table 5 show how age, sex, and a time trend affect the transition from one state of impairment to another. ${ }^{35}$ As these are difficult to interpret in isolation, we show how

other betas to vary. We use the Matlab fminsearch function to refine our estimate. We then remove the constraint on the values of $\boldsymbol{\beta}_{3}-\boldsymbol{\beta}_{7}$ and re-estimate the values of all the betas, again using fminsearch. A potential danger is that our algorithm might arrive at a local rather than a global minimum. We therefore tested our algorithm by creating simulated data given assumed transition probabilities, calculating sample characteristics, and checking that our computational technique can recover betas that yield the assumed transition probabilities. We adjusted the weights of the various statistics we sought to match to give somewhat less weight individually to statistics that capture correlated features of the data, for example, the percentages of the sample staying in a nursing home more than one, three, or five years.

${ }^{34}$ We generate 10,000 Monte Carlo simulations of combined health and care states, a 10,000 by 553 months by 2 (health state and care state) matrix. We calculate the percentages of people aged 65 who were in a care state at month $t$, and compute the percentages in each care states at $t+1$, yielding an unconditional transition matrix for that care state.

${ }^{35}$ As we are fitting parameters to match moments of the data and of Monte Carlo simulations, conventional standard errors depend arbitrarily on the number of simulations. 
well the model estimates fit the observed values of monthly impairment transitions. The two panels of Table 6 compare the observed and fitted 1999-2004 transition matrices for females aged 75-84 in 1999. The percentages in each row sum to 100 . To illustrate, 49.5 percent of women who were free of disability in 1999 were also free of disability in 2004. The model predicts a value of 52.5 percent, which is relatively close. For those who were well in 1999, the next most likely transition is to state 2, experiencing an inability to perform IADLs (22.7\% observed, $19.9 \%$ predicted) and then to state 8 , death (15.3\% observed, $16.6 \%$ predicted). Meanwhile, among those in state 3, with 1 ADL limitation in 1999, some returned to wellness (13.8\% observed, 9.2\% fitted). Overall, the fitted values are close to the observed values. ${ }^{36}$

\section{The care status transition matrices}

Table 7 reports the coefficient estimates for $\boldsymbol{\beta}_{3}$ to $\boldsymbol{\beta}_{10}$ from the nursing home care transition model in equation (3), estimated separately for men and women using the method of simulated moments. As expected, an increase in the number of ADLs increases the likelihood of nursing home entry and stay, as does the onset of ADL limitations. Cognitive impairment also raises the likelihood of entry and of stay, for a given number of ADL limitations, but the onset of cognitive impairment has only a small effect on the likelihood. These effects are greater for men than for women. Table 8 compares the care characteristics of the HRS sample with those of our simulated individuals, calculated using the above coefficients. The characteristics of the simulated data are quite close to those of the HRS statistics that we match in our estimation. While it does not fully match the probability of leaving care alive, which we do not match in the estimation, it is not extremely far off either; we somewhat over-estimate it at $84 \%$ for men and women, versus $62 \%$ for men and $66 \%$ for women in the HRS. ${ }^{37}$ Among the statistics that we match, the model predicts, and the HRS reveals, that $44 \%$ of men and $58 \%$ of women will use nursing home care. We predict a slightly higher age at first use (82 years of age for men versus 80 in the HRS, and 83 versus 82 for women), a relatively low probability of staying in care for more than one year (24\% simulated versus $22 \%$ in the HRS for men and $37 \%$ versus $36 \%$ for women) and a relatively high probability of a having a single stay in a nursing home (65\% simulated and in the HRS for men and 58\% versus $55 \%$ for women). The model yields a total of

\footnotetext{
${ }^{36}$ Corresponding analyses for men and for other age groups are available from the authors on request.

${ }^{37}$ In consequence, our model will tend to over-estimate willingness to pay for long-term care insurance.
} 
46 unconditional transition matrices, one for each age from 65 to 110, and 2,576 conditional transition matrices, one for each age and for each of 56 health status transitions. An example appears in Table 9 showing the unconditional care status transition probabilities for all men aged 85. A man receiving home health care has a $92.2 \%$ chance of continuing to receive home health care in the following month, a 2.1\% chance of not needing care (returning to the "healthy" care state), a $2.2 \%$ chance of moving to assisted living, a 1.4\% chanced of moving to a nursing home, and a $2.1 \%$ chance of dying. The full set of transition matrices are available from the authors on request.

An important issue for projecting insurance company and government payments for longterm care involves Medicare coverage rules for short-term nursing home stays. The Robinson (1996) model combines short stays following a qualifying hospital admission, which are covered by Medicare, and other stays that are potentially paid for by individuals or private insurers. While the HRS data does not permit us to identify with precision when institutionalized individuals became eligible for Medicare or Medicaid, our model yields information about the duration of stays. ${ }^{38}$ Among men and women, respectively, 32 and 22 percent of the total days spent in a nursing home in our simulated population comprises stays of three months or less, similar to the 25.2 percent of all stays that the Center for Medicare and Medicaid Services (2013) report as being covered by Medicare but higher than in earlier years. We attribute our higher percentages to the inclusion of some ineligible admissions.

The impact of revised care expectations on willingness to pay for long-term care insurance

To illustrate the impact of our revised and updated care expectations on willingness to pay for long-term care insurance, we revisit Brown and Finkelstein (2008), who estimate a single individuals’ willingness to pay for a \$100 daily benefit policy at market loads We recalculate willingness-to-pay using our revised transition matrix. ${ }^{39}$ In the Brown and Finkelstein model, individuals are retired and in good health at age 65. Each month, they face probabilities, varying with age and gender, of transitioning among the five care states described above. Individuals incur care costs if they receive home health care or reside in a nursing home or assisted living

\footnotetext{
${ }^{38}$ Individuals are asked whether their nursing home stays were completely covered by health insurance, mostly covered, only partially covered, or not covered at all. Although in theory one could estimate Medicare coverage by eliminating individuals with long-term care insurance, in practice, the data is of insufficient quality.

${ }^{39}$ We use the transition matrix to calculate both premiums and willingness to pay, thus ensuring that the same sales load is used in both base case and counterfactual.
} 
facility. The model carefully replicates relevant features of the Medicaid program that affect willingness-to-pay.

Brown and Finkelstein (2008) assume, though, that Medicare does not cover any part of nursing home costs. In reality, Medicare acts as the primary payer for a maximum of 100 days when care is provided in a skilled nursing facility following a hospital stay of more than three consecutive days. Its primary payer status for this duration should reduce willingness-to-pay for private insurance, but it is difficult to gauge its full importance because the HRS does not identify episodes of Medicare-covered care. Our estimates show that 49.9 percent of men and 39.0 percent of women who use nursing home care never have a stay exceeding three months, and these stays comprise 11.7 and 9.0 percent of the total number of nights spent in nursing homes. As Medicare covers approximately 25 percent of nursing home costs, and presumably also nursing home nights, it seems likely that many of these short stays and also the first months of some longer stays are covered by Medicare. ${ }^{40}$ The study calculates an upper-bound estimate of the effect of Medicare on willingness-to-pay by assuming that the first three months of all episodes of care are covered by Medicare. ${ }^{41}$

The individual's goal in the Brown and Finkelstein model is to choose consumption each period to maximize expected lifetime utility, discounted by a rate of time preference which they assume to be three percent. They also assume constant relative risk aversion with a coefficient of three. The model is solved numerically, starting from an assumed maximum survival age, $T$. Willingness to pay for long-term care insurance is calculated by first assuming the individual purchases long-term care insurance, calculating the optimal wealth decumulation strategy, and noting expected discounted lifetime utility. Long-term insurance then becomes unavailable and the optimal decumulation strategy is recalculated. Willingness-to-pay for long-term care insurance equals the amount by which age-65 wealth must be increased so that the individual can achieve the same expected discounted lifetime utility when he does not purchase insurance. If the individual prefers not to purchase insurance, willingness to pay will be negative. Brown and

\footnotetext{
${ }^{40}$ Centers for Medicare and Medicaid Services (2013), Table 13.

${ }^{41}$ The new study shows that stays of less than three months and the first three months of longer stays comprise 32.1 percent and 28.1 percent of total nursing home nights among men and women, respectively, somewhat in excess of the 25 percent of nights that Medicare covered in 2011. Centers for Medicare and Medicaid Services (2013) data reveal that the percent of nursing home costs covered by Medicare has been trending up over time, and Medicare covered somewhat less than 25 percent during the period covered by the HRS data. The calculations assume a hypothetical policy that provides benefits only when Medicare does not meet the cost of care. In reality, individuals must choose a fixed elimination period that does not depend on whether Medicare provides benefits.
} 
Finkelstein assume that policies are sold at market loads of 50 percent for men and minus six percent for women.

Figures 1 and 2 show the amounts single men and women would be willing to pay at the $10^{\text {th }}$ to the $90^{\text {th }}$ percentile of the wealth distribution under the base case of the Robinson (1996) transition matrix and our two counterfactuals for long-term care insurance, though without any allowance for Medicare. At the $90^{\text {th }}$ percentile, men would be willing to pay $\$ 24,800$ for access to the long-term care insurance market, given the Robinson (1996) transition probabilities. Under our revised transition probabilities, willingness to pay falls to $\$ 7,300$. Under the original transition matrix, 33 percent of men and 41 percent of women had a positive willingness to pay for long-term care insurance. Under our revised transition matrix, only 22 percent of men and 34 percent of women had a positive willingness to pay; the drop of one-third for men is especially noticeable. The consequence of the overall changes in predicted nursing home use, along with changes in willingness-to-pay, is an increase in Medicaid participation at most percentiles of the wealth distribution for example rising from 3.9 to 5.9 percent for men at the $90^{\text {th }}$ percentile of wealth and from 28.2 to 33.6 percent for men at the $50^{\text {th }}$ percentile. ${ }^{42}$ Meanwhile, when Medicare covers the first three months of care, only 19 and 31 percent of men and women have a positive willingness to pay. This analysis strengthens the conclusion emphasized by Brown and Finkelstein that Medicaid crowds out much of the private long-term care insurance market. Moreover, we show that the availability of Medicare as an insurance alternative likely plays a small but significant role in explaining low levels of private insurance coverage. In sum, applying our new estimates of needing care reduces, but does not eliminate, the possible relevance of behavioral explanations of low private insurance coverage.

\section{Conclusions}

We show that the Robinson (1996) model significantly underestimates the risk of requiring long-term care and significantly overestimates the average duration of care, conditional on ever requiring care. We estimate revised transition probabilities. These transition probabilities vary with age, gender, and marital status and are available from the authors on

\footnotetext{
${ }^{42}$ The figures assume that people do not purchase long-term care insurance. If they made optimal purchase decisions about the policy we describe earlier in the text, then the figures for Medicaid participation are 3.9 and 5.2 percent for men at the $90^{\text {th }}$ percentile of wealth under the old and new transition matrices and 20.8 and 27.0 percent for men at the $50^{\text {th }}$ percentile.
} 
request. We show that the choice of transition matrix has a significant effect on willingness to pay for long-term care insurance. Our calculations based on the Brown and Finkelstein (2008) model of willingness to pay for private long-term care insurance show that single men and women above the 70th and 60th percentiles of the wealth distribution have a positive willingness to pay for long term care insurance at market loads when the Robinson transition matrix is used. But, only 22 and 34 have a positive willingness to pay when our revised transition matrix is used, somewhat closer to the 14 percent coverage rate that we observe in the HRS.

Our research helps to resolve the puzzle of low private long-term care insurance coverage. We show that, when we re-estimate the Brown and Finkelstein model using our revised transition matrix, Medicaid crowd-out provides an even stronger explanation for the low level of coverage among single individuals than previously thought. Friedberg et. al. (2014) engages in similar calculations for married couples. The rest of the long-term care insurance puzzle may be explained by mis-specifications of preferences, omission of other insurance policy features that deter purchase, or behavioral explanations involving myopia or ignorance. 


\section{References}

Ameriks, John, Andrew Caplin, Steven Laufer, and Stijn Van Nieuwerburgh. 2011. “The Joy of Giving or Assisted Living? Using Strategic Surveys to Separate Public Care Aversion from Bequest Motives.” Journal of Finance 55(2): 519-561.

Arling, Greg, Shelley Hagan, and Harald Buhaug. “The Feasibility of a Public-Private LongTerm Care Financing Plan.” Medical Care 1992(30): 699.

Brown, Jeffrey R., and Amy Finkelstein. 2004. “The Interaction of Public and Private Insurance: Medicaid and the Long-Term Care Insurance Market.” Working Paper 10989. Cambridge, MA: National Bureau of Economic Research.

Brown, Jeffrey R., and Amy Finkelstein. 2008. “The Interaction of Public and Private Insurance: Medicaid and the Long-Term Care Insurance Market.” American Economic Review 98(3): 1083-1102.

Byrne, David, Michelle Goeree, Bridget Hiedemann, and Steven Stern. 2009. "Formal Home Health Care, Informal Care, and Family Decision-Making.” International Economic Review 50(4): 1205-1242.

Cohen, Marc A., Jocelyn Gordon, and Jessica Miller. 2011. "Understanding How Long-Term Care Benefit Triggers Are Implemented in the Private Insurance Setting.” CLASS Technical Assistance Brief Series 3. Long Beach, CA: The SCAN Foundation.

Cohen, Marc A., Eileen J. Tell., and Stanley S. Wallack. 1986. "The Lifetime Risks and Costs of Nursing Home Use Among the Elderly.” Medical Care 41(6): 785-792.

Centers for Medicare and Medicaid Services. 2013. "National Health Expenditure Projections 2012-2022.” Available at: http://www.cms.gov/Research-Statistics-Data-andSystems/Statistics-Trends-andReports/NationalHealthExpendData/downloads/proj2012.pdf.

Costa-Font, Joan, and Christophe Courbage. 2014. "Crowding Out of Long-Term Care Insurance: Evidence from European Expectations Data.” Working Paper 4910. München, Germany: CESifo.

Dick, Andrew, Alan M. Garber, and Thomas E. MaCurdy. 1994. "Forecasting Nursing Home Utilization of Elderly Americans.” in Studies in the Economics of Aging. Chicago, IL: University of Chicago Press: 365-394.

Fong, Joelle H., Adam W. Shao, and Michael Sherris. 2013. "Multi-State Actuarial Models of Functional Disability.” Research Paper 2013ACTL14. Sydney, Australia: Australian School of Business. 
Friedberg, Leora, Wei Sun, and Anthony Webb. 2014. "Medicaid and Crowd-out of Long-Term Care Insurance.” Unpublished working paper.

Gustman, Alan, and Thomas Steinmeier. 2005. “The Social Security Early Entitlement Age in a Structural Model of Retirement and Wealth.” Journal of Public Economics 89 (2-3): 441-463.

Hiedemann, Bridget, Michelle Sovinsky, and Steven Stern. 2013. "Will You Still Want Me Tomorrow? The Dynamics of Families’ Long-Term Care Arrangements.” Manuscript. University of Virginia.

Hurd, Michael, Pierre-Carl Michaud, and Susann Rohwedder. 2014. "The Lifetime Risk of Nursing Home Use.” In Discoveries in the Economics of Aging edited by David A. Wise, 81-109. Chicago, IL: University of Chicago Press.

Kelly, Anne, Jessamyn Conell-Price, Kenneth Covinsky, Irena Stijacic Cenzer, Anna Chang, W. John Boscardin, and Alexaner K. Smith. 2010. "Length of Stay for Older Adults Residing in Nursing Homes at the End of Life.” Journal of the American Geriatrics Society 58(9): 1701-1706.

Kemper, Peter, and Christopher M. Murtaugh. 1991. "Lifetime Use of Nursing Home Care.” New England Journal of Medicine 324: 595-600.

Liang, Jersey, Xian Liu, Edward Tu, and Nancy Whitelaw. 1996. "Probabilities and Lifetime Durations of Short-Stay Hospital and Nursing Home Use in the United States, 1985.” Medical Care 34(10): 1018-1036.

Manton, Kenneth G., and Xiliang Gu. 2001. "Changes in the Prevalence of Chronic Disability in the United States Black and Non-Black Population Above 65 from 1982 to 1999.” Proceedings of the National Academy of Sciences of the United States of America 98: 6354-59.

Manton, Kenneth G., Xiliang Gu, and Vicki L. Lamb. 2006. “Change in Chronic Disability from 1982 to 2004/2005 as Measured by Long-Term Changes in Function and Health in the U.S. Elderly Population.” Proceedings of the National Academy of Sciences of the United States of America 103(48): 18374-79.

Pezzin, Liliana, and Barbara Schone. 1999. “Intergenerational Household Formation, Female Labor Supply and Informal Caregiving: A Bargaining Approach.” Journal of Human Resources 34(3): 475-503.

Reichling, Felix and Kent Smetters. 2013. “Optimal Annuitization with Stochastic Mortality Probabilities.” Working Paper 2013-05. Washington, DC: Congressional Budget Office.

Robinson, Jim. 1996. “A Long-Term Care Status Transition Model.” Atlanta, GA: The Old-Age Crisis: Actuarial Opportunities: The 1996 Bowles Symposium. 
Rubin, Donald. 1987. Multiple Imputation for Nonresponse in Surveys. New York, NY: J. Wiley \& Sons.

Spillman, Brenda C. and James Lubitz. 2002. "New Estimates of Lifetime Nursing Home Use: Have Patterns of Use Changed?” Medical Care 40(10): 965-975.

Stallard, Eric. 2011. "Estimates of the Incidence, Prevalence, Duration, Intensity, and Cost of Chronic Disability among the U.S. Elderly.” North American Actuarial Journal 15(1): 32-58.

Stallard, Eric and Robert K.W. Yee. 1999. "Non-Insured Home and Community-Based LongTerm Care Incidence and Continuance Tables.” Schaumburg, IL: Society of Actuaries Long-Term Care Experience Committee.

Sun, Wei and Anthony Webb. 2013. "Can Long-Term Care Insurance Partnership Programs Increase Coverage and Reduce Medicaid Costs?” Working Paper 2013-8. Chestnut Hill, MA: Center for Retirement Research at Boston College.

U.S. Department of Health and Human Services. 2009. "The National Nursing Home Survey: 2004 Overview.” Vital and Health Statistics Series 13, No.167. Hyattsville, MD: Centers for Disease Control and Prevention. 
Figure 1. Willingness to Pay for Private LTCI (\$100 Daily Benefit Cap, Market Load)

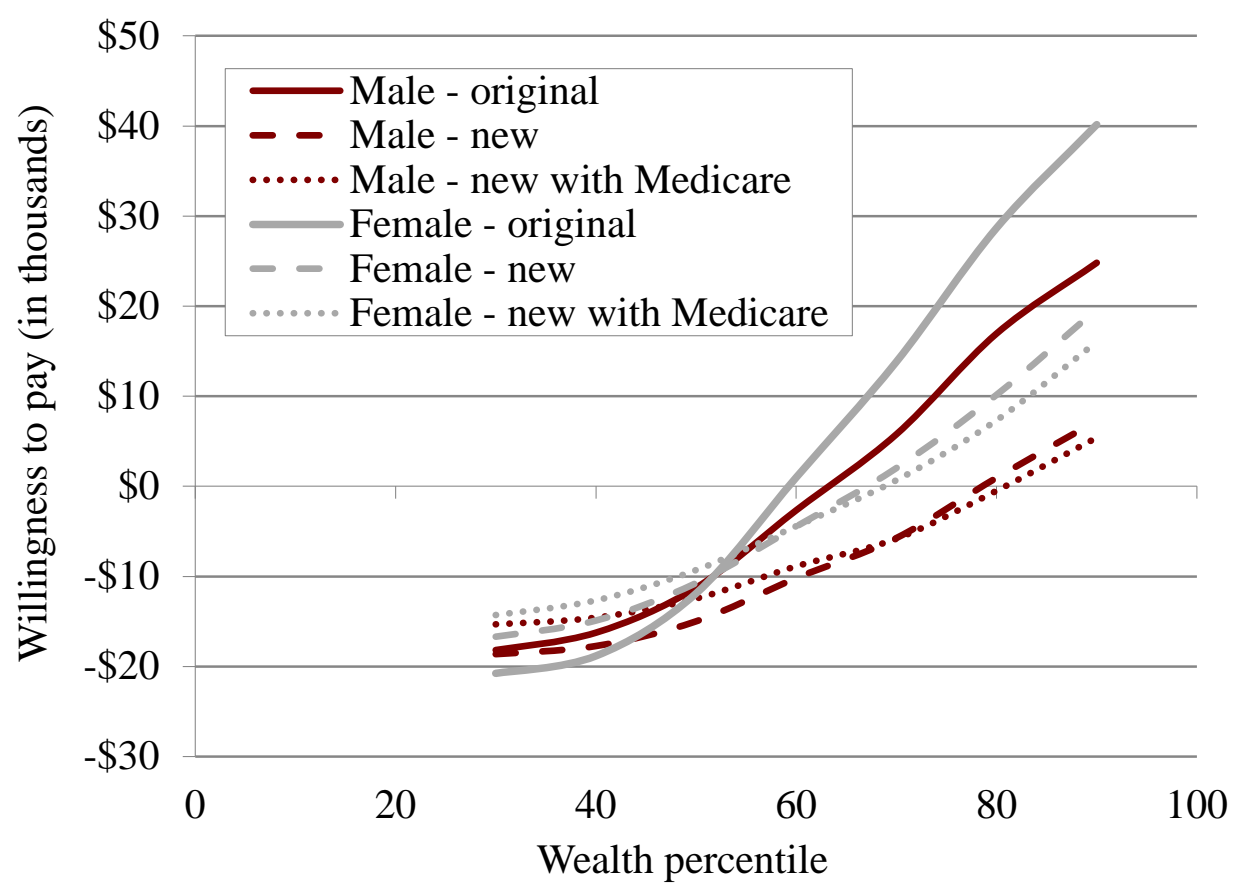

Figure 2. Willingness to Pay for Private LTCI (Comprehensive Policy, No Load)

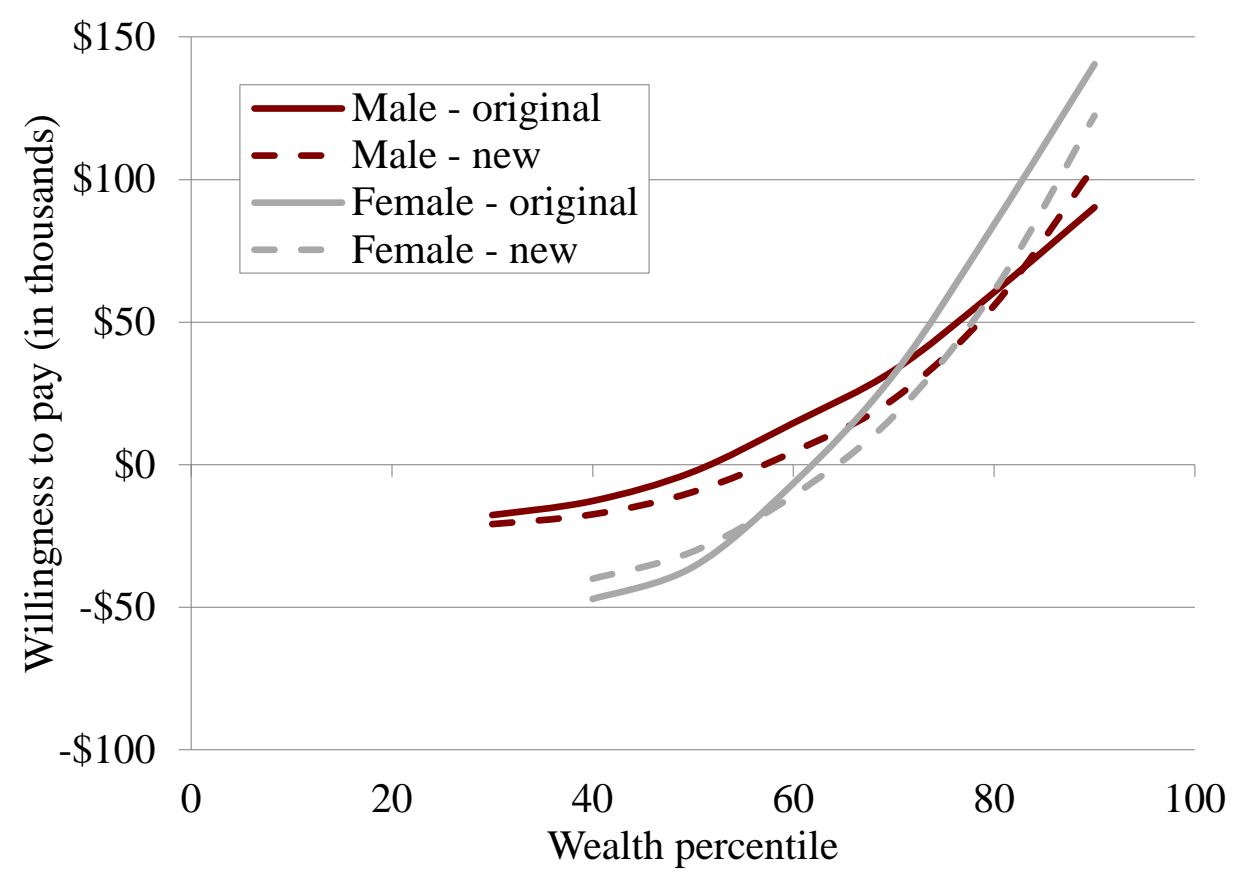


Table 1. Previous Estimates of Long-Term Care Utilization

\begin{tabular}{|c|c|c|c|c|c|c|c|c|c|}
\hline & $\begin{array}{l}\text { Arling, } \\
\text { Hagan, and } \\
\text { Buhang }\end{array}$ & $\begin{array}{c}\text { Kemper and } \\
\text { Murtaugh }\end{array}$ & $\begin{array}{c}\text { Cohen, Tell, and } \\
\text { Wallack }\end{array}$ & $\begin{array}{c}\text { Dick, } \\
\text { Garber, and } \\
\text { MaCurdy }\end{array}$ & Kelly et.al. & $\begin{array}{l}\text { Liang, Liu,Tu, } \\
\text { and Whitelaw }\end{array}$ & $\begin{array}{l}\text { Spillman and } \\
\text { Lubitz }\end{array}$ & $\begin{array}{c}\text { Hurd, } \\
\text { Michaud, and } \\
\text { Rohwedder }\end{array}$ & Robinson \\
\hline Dataset used & $\begin{array}{c}\text { Wisconsin } \\
\text { LTC Use and } \\
\text { Cost Model }\end{array}$ & $\begin{array}{c}1986 \text { Mortality } \\
\text { Followback Survey }\end{array}$ & $\begin{array}{c}1977 \text { Current } \\
\text { Medicare Survey }\end{array}$ & $\begin{array}{l}\text { NLTCS, } \\
\text { NNHS }\end{array}$ & $\begin{array}{l}\text { HRS ( } 7 \\
\text { waves of } \\
\text { AHEAD } \\
\text { data) }\end{array}$ & $\begin{array}{c}1985 \text { NNHS, } \\
1985 \\
\text { NHDS,1987 } \\
\text { National Medical } \\
\text { Care Expenditure } \\
\text { Survey }\end{array}$ & $\begin{array}{c}\text { National } \\
\text { Mortality } \\
\text { Followback } \\
\text { Survey }\end{array}$ & $\begin{array}{c}\text { HRS, Waves } \\
1-10\end{array}$ & NLTCS \\
\hline Period covered & 1987-1989 & Pre 1986 & $1977-1978$ & 1982-1984 & 1992-2006 & 1985 & $\begin{array}{c}\text { 1986, 1993, } \\
\text { and } 2000 \\
\text { (projected) }\end{array}$ & $1992-2010$ & 1982-1989 \\
\hline Uses exit data & Yes & Yes & Yes & Yes & Yes & No & Yes & Yes & Yes \\
\hline \multicolumn{10}{|l|}{$\begin{array}{l}\text { Estimate of } \\
\text { probability of using } \\
\text { care after age 65: }\end{array}$} \\
\hline Males & \multirow{2}{*}{$55 \%$} & $33 \%$ & $31 \%$ & $36 \%$ & Not reported & Not reported & $33 \%$ & $50 \%$ & $27 \%$ \\
\hline Females & & $52 \%$ & $52 \%$ & $35 \%$ & Not reported & Not reported & $47 \%$ & $65 \%$ & $44 \%$ \\
\hline \multicolumn{10}{|l|}{$\begin{array}{l}\text { Unconditional } \\
\text { mean duration of } \\
\text { care in years } \\
\end{array}$} \\
\hline Males & \multirow{2}{*}{1.12} & Not reported & Not reported & 0.48 & Not reported & \multirow{2}{*}{2.28} & \multirow{2}{*}{1.1} & 0.38 & 0.35 \\
\hline Females & & Not reported & Not reported & 0.73 & Not reported & & & 0.78 & 0.88 \\
\hline \multicolumn{10}{|l|}{$\begin{array}{l}\text { Conditional mean } \\
\text { duration in years }\end{array}$} \\
\hline Males & \multirow{2}{*}{2.04} & Not reported & Not reported & 1.34 & 0.86 & Not reported & \multirow{2}{*}{2.5} & 0.76 & 1.30 \\
\hline Females & & Not reported & Not reported & 2.09 & 1.33 & Not reported & & 1.20 & 2.00 \\
\hline
\end{tabular}


Table 1. Previous Estimates of Long-Term Care Utilization (cont'd)

\begin{tabular}{|c|c|c|c|c|c|c|c|c|c|}
\hline & $\begin{array}{l}\text { Arling, } \\
\text { Hagan, and } \\
\text { Buhang }\end{array}$ & $\begin{array}{c}\text { Kemper and } \\
\text { Murtaugh }\end{array}$ & $\begin{array}{c}\text { Cohen, Tell, and } \\
\text { Wallack }\end{array}$ & $\begin{array}{c}\text { Dick, } \\
\text { Garber, and } \\
\text { MaCurdy }\end{array}$ & Kelly et.al. & $\begin{array}{l}\text { Liang, Liu,Tu, } \\
\text { and Whitelaw }\end{array}$ & $\begin{array}{c}\text { Spillman and } \\
\text { Lubitz }\end{array}$ & $\begin{array}{c}\text { Hurd, } \\
\text { Michaud, and } \\
\text { Rohwedder }\end{array}$ & Robinson \\
\hline Other results & & $\begin{array}{l}\text { Project } 14 \% \text { of men } \\
\text { and } 31 \% \text { women } \\
\text { aged } 65 \text { in } 1990 \text { will } \\
\text { spend more than a } \\
\text { year in nursing home }\end{array}$ & $\begin{array}{l}\text { 25\% chance of } \\
\text { spending more than a } \\
\text { year, conditional on } \\
\text { entry }\end{array}$ & & & & & & \\
\hline $\begin{array}{l}\text { Research } \\
\text { methodology }\end{array}$ & $\begin{array}{l}\text { Simulations } \\
\text { based on } \\
\text { Wisconsin } \\
\text { LTC Use and } \\
\text { Cost Model }\end{array}$ & $\begin{array}{l}\text { Retrospective study } \\
\text { based on interviews } \\
\text { with next of kin }\end{array}$ & $\begin{array}{l}\text { Nursing home entry } \\
\text { inferred from data on } \\
\text { whether the } \\
\text { respondent had been } \\
\text { visited by a physician } \\
\text { in a nursing home. }\end{array}$ & $\begin{array}{l}\text { Simulations } \\
\text { based on } \\
\text { 1982-84 } \\
\text { NLTCS data }\end{array}$ & $\begin{array}{c}\text { Sample } \\
\text { limited to } \\
\text { individuals } \\
\text { who died in a } \\
\text { nursing home }\end{array}$ & $\begin{array}{l}\text { Construct multi } \\
\text { state life table } \\
\text { based on age- } \\
\text { specific transition } \\
\text { probabilities }\end{array}$ & $\begin{array}{l}\text { Retrospective } \\
\text { study based } \\
\text { on interviews } \\
\text { with next of } \\
\text { kin. }\end{array}$ & $\begin{array}{c}\text { Analysis of } \\
\text { HRS panel } \\
\text { data }\end{array}$ & $\begin{array}{l}\text { Uses NLTCS to } \\
\text { estimate health status } \\
\text { transition probabilities. } \\
\text { Assigns care status } \\
\text { conditional on health } \\
\text { status }\end{array}$ \\
\hline
\end{tabular}

Notes: HRS = Health and Retirement Study. NLTCS = National Long-Term Care Survey. NNHS = National Nursing Home Survey. AHEAD = Asset and Health Dynamics among the oldest old. NHDS = National Hospital Discharge Survey. Kemper and Murtaugh estimates are for birth cohort turning 65 in 1990. Hurd, Michaud, and Rohwedder calculate utilization from age 50. 
Table 2. Comparison of Robinson with HRS Sample Statistics on Nursing Home Use

\begin{tabular}{lrrrrr}
\hline & \multicolumn{2}{c}{ Men } & & \multicolumn{2}{c}{ Women } \\
\cline { 2 - 3 } \cline { 5 - 6 } & Robinson & HRS & & Robinson & HRS \\
\hline Percent using & 0.27 & 0.44 & & 0.44 & 0.58 \\
Mean age of first use & 83 & 80 & & 84 & 82 \\
Mean years in care: & & & & & \\
Unconditional & 0.35 & 0.37 & & 0.88 & 0.79 \\
Conditional on ever using & 1.30 & 0.85 & & 2.00 & 1.37 \\
Probability of using for: & & & & \\
1 year & 0.33 & 0.22 & & 0.42 & 0.36 \\
3 years & 0.12 & 0.08 & 0.22 & 0.15 \\
5 years & 0.05 & 0.02 & & 0.12 & 0.07 \\
Conditional probability of ever exiting alive & 0.65 & 0.62 & & 0.66 & 0.66 \\
Conditional probability of only one stay & 0.75 & 0.65 & 0.65 & 0.55 \\
\hline Notes: Robnson data is as reported in Table 1 of Brown and Finkelstein (2008) and authors' calculations. HRS data \\
is authors' calculations
\end{tabular}


Table 3A. Care Status of HRS Participants

\begin{tabular}{|c|c|c|c|c|c|c|c|c|c|c|}
\hline Age & $55-59$ & $60-64$ & $65-69$ & $70-74$ & $75-79$ & $80-84$ & $85-89$ & $90-94$ & $95+$ & All 65+ \\
\hline \multicolumn{11}{|l|}{ Males } \\
\hline \multicolumn{11}{|l|}{ Percentages: } \\
\hline In nursing home at interview & 0.3 & 0.5 & 1.1 & 2.1 & 4.0 & 7.1 & 14.3 & 27.2 & 40.0 & 5.3 \\
\hline Any nursing home last two years & 0.8 & 1.1 & 2.2 & 4.5 & 6.9 & 12.4 & 21.3 & 34.7 & 42.5 & 8.5 \\
\hline In assisted living at interview & 0.1 & 0.3 & 0.7 & 1.4 & 2.5 & 4.5 & 5.5 & 7.9 & 3.7 & 3.3 \\
\hline Any home health care last two years & 3.5 & 5.1 & 6.5 & 9.6 & 13.2 & 17.2 & 22.9 & 31.8 & 37.8 & 12.6 \\
\hline \multicolumn{11}{|l|}{ Number of: } \\
\hline Stays last two years & 1.27 & 1.10 & 1.13 & 1.32 & 1.25 & 1.41 & 1.12 & 1.26 & 1.15 & 1.23 \\
\hline Nights last two years & 187 & 195 & 166 & 225 & 231 & 264 & 233 & 268 & 271 & 243 \\
\hline \multicolumn{11}{|l|}{ Females } \\
\hline \multicolumn{11}{|l|}{ Percentages: } \\
\hline In nursing home at interview & 0.2 & 0.6 & 1.3 & 1.9 & 4.1 & 8.8 & 19.5 & 34.2 & 50.3 & 8.5 \\
\hline Any nursing home last two years & 0.6 & 1.5 & 2.9 & 5.2 & 8.6 & 15.0 & 27.7 & 42.0 & 57.4 & 13.0 \\
\hline In assisted living at interview & 0.1 & 0.2 & 0.3 & 1.2 & 3.2 & 3.8 & 6.1 & 5.1 & 1.8 & 3.3 \\
\hline Any home health care last two years & 3.6 & 5.3 & 7.8 & 10.4 & 14.2 & 18.9 & 26.8 & 35.8 & 43.0 & 15.6 \\
\hline \multicolumn{11}{|l|}{ Number of: } \\
\hline Stays last two years & 1.23 & 1.11 & 1.22 & 1.27 & 1.12 & 1.21 & 1.14 & 1.16 & 1.30 & 1.19 \\
\hline Nights last two years & 216 & 172 & 205 & 233 & 268 & 290 & 303 & 330 & 356 & 300 \\
\hline
\end{tabular}

Notes: Authors' calculations. HRS sample weights. Includes data from exit interviews. 
Table 3B. Care Status of HRS Participants - 2004 Wave Only

\begin{tabular}{|c|c|c|c|c|c|c|c|c|c|c|}
\hline Age & $55-59$ & $60-64$ & $65-69$ & $70-74$ & $75-79$ & $80-84$ & $85-89$ & $90-94$ & $95+$ & All 65+ \\
\hline \multicolumn{11}{|l|}{ Males } \\
\hline \multicolumn{11}{|l|}{ Percentages: } \\
\hline In nursing home at interview & 0.0 & 0.6 & 0.8 & 2.5 & 3.4 & 7.1 & 11.7 & 25.6 & 41.6 & 4.9 \\
\hline Any nursing home last two years & 0.3 & 0.8 & 4.3 & 4.3 & 6.3 & 13.0 & 18.7 & 31.8 & 40.1 & 7.9 \\
\hline In assisted living at interview & 0.0 & 0.5 & 0.9 & 1.4 & 3.3 & 2.9 & 2.6 & 2.6 & 7.4 & 2.3 \\
\hline Any home health care last two years & 3.3 & 4.1 & 5.7 & 8.0 & 11.6 & 15.4 & 21.7 & 30.2 & 39.9 & 11.3 \\
\hline \multicolumn{11}{|l|}{ Number of: } \\
\hline Stays last two years & 1.00 & 1.09 & 1.12 & 1.08 & 1.06 & 1.14 & 1.08 & 1.21 & 1.05 & 1.11 \\
\hline Nights last two years & 0 & 351 & 210 & 179 & 190 & 214 & 227 & 253 & 201 & 214 \\
\hline \multicolumn{11}{|l|}{ Females } \\
\hline \multicolumn{11}{|l|}{ Percentages: } \\
\hline In nursing home at interview & 0.2 & 0.3 & 1.4 & 1.6 & 4.0 & 8.0 & 19.0 & 37.4 & 54.5 & 8.1 \\
\hline Any nursing home last two years & 0.5 & 1.4 & 2.3 & 5.0 & 8.3 & 13.2 & 26.6 & 44.1 & 60.6 & 12.2 \\
\hline In assisted living at interview & 0.0 & 0.0 & 0.4 & 0.9 & 5.0 & 1.9 & 6.6 & 6.3 & 2.1 & 3.3 \\
\hline Any home health care last two years & 3.6 & 5.4 & 7.0 & 10.0 & 12.3 & 17.8 & 26.2 & 33.7 & 38.1 & 14.3 \\
\hline \multicolumn{11}{|l|}{ Number of: } \\
\hline Stays last two years & 1.00 & 1.02 & 1.17 & 1.12 & 1.06 & 1.23 & 1.08 & 1.06 & 1.27 & 1.13 \\
\hline Nights last two years & 321 & 341 & 355 & 323 & 258 & 399 & 333 & 342 & 337 & 337 \\
\hline
\end{tabular}

Notes: Authors' calculations. HRS sample weights. Includes data from exit interviews. 
Table 4A. Comparison of Health Status 1984 and 2004 NLTCS

\begin{tabular}{|c|c|c|c|c|c|c|c|c|}
\hline Age & $65-69$ & $70-74$ & $75-79$ & $80-84$ & $85-89$ & $90-94$ & $95+$ & All 65+ \\
\hline NLTCS wave & \multicolumn{8}{|c|}{1984} \\
\hline \multicolumn{9}{|l|}{ Men } \\
\hline Well & $90.9 \%$ & $86.6 \%$ & $81.0 \%$ & $71.0 \%$ & $54.2 \%$ & $33.6 \%$ & $2.8 \%$ & $80.8 \%$ \\
\hline Unable to perform IADL but no ADLs & 5.4 & 7.5 & 10.9 & 15.0 & 20.9 & 22.1 & 28.9 & 10.0 \\
\hline \multicolumn{9}{|l|}{ No cognitive impairment and: } \\
\hline Unable to perform $1 \mathrm{ADL}$ & 1.1 & 1.5 & 1.3 & 3.0 & 5.0 & 9.2 & 20.7 & 2.0 \\
\hline Unable to perform $2 \mathrm{ADLs}$ & 0.5 & 0.6 & 0.8 & 0.9 & 2.6 & 5.6 & 8.4 & 0.9 \\
\hline Unable to perform 3+ ADLs & 1.1 & 1.5 & 2.7 & 4.0 & 8.2 & 11.1 & 16.0 & 2.7 \\
\hline \multicolumn{9}{|l|}{ Cognitive impairment and: } \\
\hline Unable to perform $<2$ ADLs & 0.5 & 1.5 & 1.6 & 2.6 & 5.5 & 6.3 & 7.2 & 1.8 \\
\hline Unable to perform 2+ ADLs & 0.5 & 0.8 & 1.7 & 3.5 & 3.6 & 12.1 & 16.0 & 1.8 \\
\hline \multicolumn{9}{|l|}{ Women } \\
\hline Well & $88.8 \%$ & $83.5 \%$ & $75.4 \%$ & $61.0 \%$ & $42.0 \%$ & $22.8 \%$ & $11.7 \%$ & $71.0 \%$ \\
\hline Unable to perform IADL & 7.2 & 10.3 & 13.2 & 17.6 & 19.8 & 17.8 & 15.9 & 12.8 \\
\hline \multicolumn{9}{|l|}{ No cognitive impairment and: } \\
\hline Unable to perform $1 \mathrm{ADL}$ & 1.4 & 2.4 & 3.1 & 5.7 & 7.9 & 10.8 & 12.8 & 4.0 \\
\hline Unable to perform $2 \mathrm{ADLs}$ & 0.6 & 0.5 & 1.0 & 1.3 & 2.0 & 3.1 & 7.7 & 1.1 \\
\hline Unable to perform $3+$ ADLs & 1.0 & 1.6 & 3.2 & 6.0 & 11.0 & 20.6 & 28.5 & 4.8 \\
\hline \multicolumn{9}{|l|}{ Cognitive impairment and: } \\
\hline Unable to perform $<2$ ADLs & 0.5 & 1.0 & 2.6 & 4.2 & 8.8 & 9.1 & 6.8 & 3.1 \\
\hline Unable to perform 2+ ADLs & 0.5 & 0.7 & 1.5 & 4.2 & 8.5 & 15.8 & 16.6 & 3.2 \\
\hline
\end{tabular}


Table 4A. Comparison of Health Status 1984 and 2004 NLTCS (cont'd)

\begin{tabular}{|c|c|c|c|c|c|c|c|c|}
\hline Age & 65-69 & $70-74$ & $75-79$ & $80-84$ & $85-89$ & $90-94$ & $95+$ & All 65+ \\
\hline NLTCS wave & \multicolumn{8}{|c|}{2004} \\
\hline \multicolumn{9}{|l|}{ Men } \\
\hline Well & $94.3 \%$ & $90.0 \%$ & $86.4 \%$ & $79.7 \%$ & $65.4 \%$ & $52.7 \%$ & $36.0 \%$ & $86.3 \%$ \\
\hline Unable to perform I ADL & 3.5 & 4.8 & 4.6 & 7.9 & 15.6 & 21.5 & 23.0 & 6.0 \\
\hline \multicolumn{9}{|l|}{ No cognitive impairment and: } \\
\hline Unable to perform $1 \mathrm{ADL}$ & 1.0 & 2.1 & 3.5 & 4.7 & 6.6 & 4.8 & 8.4 & 2.8 \\
\hline Unable to perform $2 \mathrm{ADLs}$ & 0.2 & 0.4 & 1.1 & 1.5 & 2.3 & 6.5 & 3.2 & 0.9 \\
\hline Unable to perform $3+$ ADLs & 0.6 & 1.6 & 2.5 & 3.4 & 5.8 & 6.0 & 19.7 & 2.2 \\
\hline \multicolumn{9}{|l|}{ Cognitive impairment and: } \\
\hline Unable to perform $<2$ ADLs & 0.3 & 0.5 & 1.2 & 1.2 & 3.6 & 3.8 & 6.5 & 1.0 \\
\hline Unable to perform $2+$ ADLs & 0.2 & 0.6 & 0.7 & 1.5 & 0.6 & 4.7 & 3.3 & 0.7 \\
\hline \multicolumn{9}{|l|}{ Women } \\
\hline Well & $90.5 \%$ & $88.2 \%$ & $80.6 \%$ & $67.7 \%$ & $54.0 \%$ & $36.4 \%$ & $20.6 \%$ & $77.3 \%$ \\
\hline Unable to perform I ADL & 4.3 & 5.0 & 7.9 & 12.5 & 14.9 & 19.0 & 16.2 & 8.4 \\
\hline \multicolumn{9}{|l|}{ No cognitive impairment and: } \\
\hline Unable to perform $1 \mathrm{ADL}$ & 3.3 & 4.0 & 5.1 & 8.0 & 10.3 & 11.9 & 10.7 & 5.8 \\
\hline Unable to perform $2 \mathrm{ADLs}$ & 0.6 & 0.9 & 1.4 & 1.9 & 3.2 & 4.6 & 4.6 & 1.5 \\
\hline Unable to perform $3+$ ADLs & 0.8 & 1.6 & 3.0 & 5.3 & 11.8 & 16.6 & 32.0 & 4.4 \\
\hline \multicolumn{9}{|l|}{ Cognitive impairment and: } \\
\hline Unable to perform $<2$ ADLs & 0.3 & 0.2 & 0.9 & 1.9 & 2.7 & 4.7 & 4.4 & 1.1 \\
\hline Unable to perform $2+$ ADLs & 0.2 & 0.1 & 1.2 & 2.8 & 3.2 & 6.9 & 11.5 & 1.5 \\
\hline
\end{tabular}

Notes: Authors' calculations. PNAS weights. 
Table 4B. Comparison of Care Status 1984 and 2004 NLTCS

\begin{tabular}{|c|c|c|c|c|c|c|c|c|}
\hline Age & $65-69$ & $70-74$ & $75-79$ & $80-84$ & $85-89$ & $90-94$ & $95+$ & all $65+$ \\
\hline NLTCS Wave & \multicolumn{8}{|c|}{1984} \\
\hline \multicolumn{9}{|l|}{ Men } \\
\hline Receiving home health care & $0.4 \%$ & $0.8 \%$ & $1.0 \%$ & $2.3 \%$ & $2.8 \%$ & $7.8 \%$ & $11.8 \%$ & $1.3 \%$ \\
\hline In assisted living & 0.7 & 1.1 & 1.4 & 2.1 & 3.4 & 1.6 & 6.3 & 1.4 \\
\hline In nursing home & 1.1 & 2.0 & 3.8 & 6.5 & 11.8 & 27.4 & 39.7 & 4.1 \\
\hline \multicolumn{9}{|l|}{ Women } \\
\hline Receiving home health care & $0.5 \%$ & $0.8 \%$ & $1.5 \%$ & $2.1 \%$ & $3.7 \%$ & $5.7 \%$ & $3.1 \%$ & $1.7 \%$ \\
\hline In assisted living & 1.2 & 1.8 & 3.3 & 4.4 & 4.7 & 5.3 & 5.2 & 2.9 \\
\hline In nursing home & 1.3 & 2.5 & 4.9 & 11.7 & 22.4 & 37.6 & 53.6 & 8.8 \\
\hline NLTCS Wave & \multicolumn{8}{|c|}{2004} \\
\hline \multicolumn{9}{|l|}{ Men } \\
\hline Receiving home health care & $0.5 \%$ & $0.8 \%$ & $1.4 \%$ & $1.6 \%$ & $2.4 \%$ & $5.0 \%$ & $5.4 \%$ & $1.2 \%$ \\
\hline In assisted living & 0.1 & 0.5 & 0.6 & 1.7 & 3.2 & 3.8 & 10.1 & 0.9 \\
\hline In nursing home & 0.5 & 1.4 & 2.3 & 4.2 & 7.6 & 9.8 & 20.9 & 2.4 \\
\hline \multicolumn{9}{|l|}{ Women } \\
\hline Receiving home health care & $1.0 \%$ & $0.7 \%$ & $1.5 \%$ & $2.4 \%$ & $3.2 \%$ & $5.5 \%$ & $6.3 \%$ & $1.8 \%$ \\
\hline In assisted living & 0.4 & 0.4 & 1.2 & 2.5 & 5.3 & 6.7 & 14.3 & 1.8 \\
\hline In nursing home & 0.3 & 1.6 & 3.4 & 6.8 & 15.9 & 20.3 & 35.1 & 5.2 \\
\hline
\end{tabular}

Notes: Authors' calculations. PNAS weights. 
Table 5. LTC Transition Rate Parameter Estimate

\begin{tabular}{|c|c|c|c|c|c|c|c|c|}
\hline \multirow[b]{2}{*}{ Starting status $\mathrm{i}$} & \multicolumn{8}{|c|}{ Ending status, $\mathrm{j}$} \\
\hline & 1 & 2 & 3 & 4 & 5 & 6 & 7 & 8 \\
\hline & \multicolumn{8}{|c|}{ aij } \\
\hline 1 & & -2.535 & -5.070 & -9.094 & -4.034 & -4.814 & -7.548 & -3.322 \\
\hline 2 & -3.919 & & -2.001 & -3.696 & -6.662 & -3.414 & -4.092 & -2.074 \\
\hline 3 & -3.495 & -1.176 & & -1.236 & -3.424 & -2.402 & -9.196 & -1.433 \\
\hline 4 & -9.425 & -3.939 & -0.819 & & -0.786 & -5.012 & -1.043 & -2.253 \\
\hline 5 & -9.794 & -2.979 & -7.211 & -2.556 & & -9.271 & -0.818 & -0.107 \\
\hline 6 & -6.800 & -2.138 & -1.970 & -4.850 & -6.407 & & -1.302 & -2.048 \\
\hline \multirow[t]{2}{*}{7} & -8.503 & -9.162 & -7.565 & -9.209 & -0.207 & -4.170 & & -8.309 \\
\hline & \multicolumn{8}{|c|}{ bij } \\
\hline 1 & & 0.066 & 0.066 & 0.066 & 0.066 & 0.066 & 0.066 & -0.498 \\
\hline 2 & 0.308 & & 0.066 & 0.066 & 0.066 & 0.066 & 0.066 & -0.498 \\
\hline 3 & 0.308 & 0.308 & & 0.066 & 0.066 & 0.066 & 0.066 & -0.498 \\
\hline 4 & 0.308 & 0.308 & 0.308 & & 0.066 & 0.066 & 0.066 & -0.498 \\
\hline 5 & 0.308 & 0.308 & 0.308 & 0.308 & & 0.066 & 0.066 & -0.498 \\
\hline 6 & 0.308 & 0.308 & 0.308 & 0.308 & 0.308 & & 0.066 & -0.498 \\
\hline \multirow[t]{2}{*}{7} & 0.308 & 0.308 & 0.308 & 0.308 & 0.308 & 0.308 & & -0.498 \\
\hline & \multicolumn{8}{|c|}{ cij } \\
\hline 1 & & 8.770 & 8.770 & 8.770 & 8.770 & 8.770 & 8.770 & 1.713 \\
\hline 2 & -2.748 & & 3.653 & 3.653 & 3.653 & 3.653 & 3.653 & 3.729 \\
\hline 3 & -2.748 & -2.748 & & 3.653 & 3.653 & 3.653 & 3.653 & 3.729 \\
\hline 4 & -2.748 & -2.748 & -2.748 & & 3.653 & 3.653 & 3.653 & 3.729 \\
\hline 5 & -2.748 & -2.748 & -2.748 & -2.748 & & 3.653 & 3.653 & 3.729 \\
\hline 6 & -2.748 & -2.748 & -2.748 & -2.748 & -2.748 & & 3.653 & 3.729 \\
\hline \multirow[t]{2}{*}{7} & -2.748 & -2.748 & -2.748 & -2.748 & -2.748 & -2.748 & & 3.729 \\
\hline & \multicolumn{8}{|c|}{ dij } \\
\hline 1 & & -0.009 & -0.009 & -0.009 & -0.009 & -0.009 & -0.009 & -0.001 \\
\hline 2 & 0.016 & & -0.009 & -0.009 & -0.009 & -0.009 & -0.009 & -0.001 \\
\hline 3 & 0.016 & 0.016 & & -0.009 & -0.009 & -0.009 & -0.009 & -0.001 \\
\hline 4 & 0.016 & 0.016 & 0.016 & & -0.009 & -0.009 & -0.009 & -0.001 \\
\hline 5 & 0.016 & 0.016 & 0.016 & 0.016 & & -0.009 & -0.009 & -0.001 \\
\hline 6 & 0.016 & 0.016 & 0.016 & 0.016 & 0.016 & & -0.009 & -0.001 \\
\hline 7 & 0.016 & 0.016 & 0.016 & 0.016 & 0.016 & 0.016 & & -0.001 \\
\hline
\end{tabular}

Notes: Authors' calculations. 
Table 6. Observed and Fitted Health Status Transition Matrices Females 75-84, 1999-2004

\begin{tabular}{|c|c|c|c|c|c|c|c|c|c|}
\hline \multirow[b]{3}{*}{1999 health status } & \multicolumn{9}{|c|}{2004 health status } \\
\hline & \multirow[b]{2}{*}{ Count } & 1 & 2 & 3 & 4 & 5 & 6 & 7 & 8 \\
\hline & & Well & IALD only & $1 \mathrm{ADL}$ & 2 ADLs & $3+\mathrm{ADLs}$ & $\begin{array}{l}\text { Less than } 2 \\
\text { ADLs + CI }\end{array}$ & $\begin{array}{c}2+\text { ADLs } \\
+ \text { CI }\end{array}$ & Deceased \\
\hline 1. Well & 3,587 & $49.4 \%$ & $22.7 \%$ & $5.2 \%$ & $1.1 \%$ & $3.0 \%$ & $1.7 \%$ & $1.6 \%$ & $15.3 \%$ \\
\hline 2. IADL only & 731 & 3.5 & 32.8 & 8.0 & 2.1 & 7.6 & 1.0 & 2.9 & 42.1 \\
\hline 3. $1 \mathrm{ADL}$ & 188 & 13.8 & 24.2 & 11.7 & 6.4 & 6.6 & 3.3 & 1.5 & 32.5 \\
\hline 4. 2 ADLs & 48 & 1.1 & 17.0 & 2.3 & 3.2 & 11.1 & 0.0 & 0.0 & 65.3 \\
\hline 5. $3+$ ADLs & 140 & 0.6 & 5.7 & 0.0 & 1.8 & 14.2 & 0.5 & 0.5 & 76.7 \\
\hline 6. Less than 2 ADLs $+C I$ & 16 & 0.0 & 11.4 & 0.0 & 0.0 & 16.4 & 0.0 & 11.5 & 60.7 \\
\hline \multirow[t]{2}{*}{ 7. $2+\mathrm{ADLs}+\mathrm{CI}$} & 22 & 0.0 & 6.6 & 0.0 & 4.4 & 4.0 & 0.0 & 6.8 & 78.2 \\
\hline & \multicolumn{9}{|c|}{ Fitted values } \\
\hline 1. Well & & $52.5 \%$ & $19.9 \%$ & $3.4 \%$ & $1.1 \%$ & $3.4 \%$ & $1.6 \%$ & $1.5 \%$ & $16.6 \%$ \\
\hline 2. IADL only & & 9.9 & 37.9 & 7.3 & 2.3 & 5.2 & 2.7 & 2.7 & 32.0 \\
\hline 3. 1 ADL & & 9.2 & 30.8 & 6.7 & 2.3 & 6.4 & 2.5 & 3.1 & 39.0 \\
\hline 4. 2 ADLs & & 5.4 & 22.4 & 5.4 & 2.2 & 8.7 & 1.9 & 3.9 & 50.1 \\
\hline 5. $3+$ ADLs & & 2.1 & 11.5 & 3.0 & 1.6 & 8.2 & 1.0 & 3.5 & 69.3 \\
\hline 6. Less than 2 ADLs + CI & & 5.7 & 26.7 & 6.5 & 2.4 & 8.9 & 3.3 & 4.2 & 42.2 \\
\hline 7. $2+\mathrm{ADLs}+\mathrm{CI}$ & & 1.9 & 11.8 & 3.3 & 1.9 & 10.5 & 1.1 & 4.4 & 65.2 \\
\hline
\end{tabular}

Notes: Authors' calculations. 
Table 7A. Coefficient Estimates for Nursing Home Entry and Stay, Male

\begin{tabular}{llcc}
\hline & \multicolumn{1}{c}{ Male } & Entry & Stay \\
\hline$\beta_{3}$ & 1 ADLs & -6.224 & -3.186 \\
$\beta_{4}$ & 2 ADLs & -5.411 & -2.577 \\
$\beta_{5}$ & 3+ ADLs & -4.634 & -1.976 \\
$\beta_{6}$ & Less than 2 ADLs + CI & -5.570 & -2.532 \\
$\beta_{7}$ & 2+ ADLs + CI & -5.242 & -2.044 \\
$\beta_{8}$ & First has ADL & 5.466 & \\
$\beta_{9}$ & First has CI & 0.022 & \\
$\beta_{10}$ & Age & 0.055 & 0.221 \\
\hline
\end{tabular}

Table 7B. Coefficient Estimates for Nursing Home Entry and Stay, Female

\begin{tabular}{llcc}
\hline & \multicolumn{1}{c}{ Female } & Entry & Stay \\
\hline$\beta_{3}$ & 1 ADLs & -6.124 & -3.158 \\
$\beta_{4}$ & 2 ADLs & -5.579 & -2.513 \\
$\beta_{5}$ & 3+ ADLs & -4.950 & -2.039 \\
$\beta_{6}$ & Less than 2 ADLs + CI & -5.553 & -2.644 \\
$\beta_{7}$ & 2+ ADLs + CI & -5.068 & -1.938 \\
$\beta_{8}$ & First has ADL & 6.140 & \\
$\beta_{9}$ & First has CI & 0.164 & \\
$\beta_{10}$ & Age & 0.022 & 0.238 \\
\hline
\end{tabular}

Note: Authors' calculations. 
Table 8. Comparison of HRS Sample with Simulated Moments on Nursing Home Use

\begin{tabular}{|c|c|c|c|c|}
\hline & \multicolumn{2}{|c|}{ Men } & \multicolumn{2}{|c|}{ Women } \\
\hline & HRS & Simulated & HRS & Simulated \\
\hline Probability of ever using nursing home care & 0.44 & 0.44 & 0.58 & 0.58 \\
\hline Average age of first use, conditional on use & 80 & 82 & 82 & 83 \\
\hline Conditional average number of years spent in care & 0.85 & 0.88 & 1.37 & 1.44 \\
\hline \multicolumn{5}{|l|}{ Conditional probability of using for more than } \\
\hline One year & 0.22 & 0.24 & 0.36 & 0.37 \\
\hline Three years & 0.08 & 0.07 & 0.15 & 0.14 \\
\hline Five years & 0.02 & 0.02 & 0.07 & 0.07 \\
\hline Conditional probability of ever exiting alive & 0.62 & 0.84 & 0.66 & 0.84 \\
\hline Conditional probability of only one stay & 0.65 & 0.65 & 0.55 & 0.58 \\
\hline
\end{tabular}

Note: Authors' calculations. 
Table 9. Monthly Care Status Transition Probabilities at Age 85

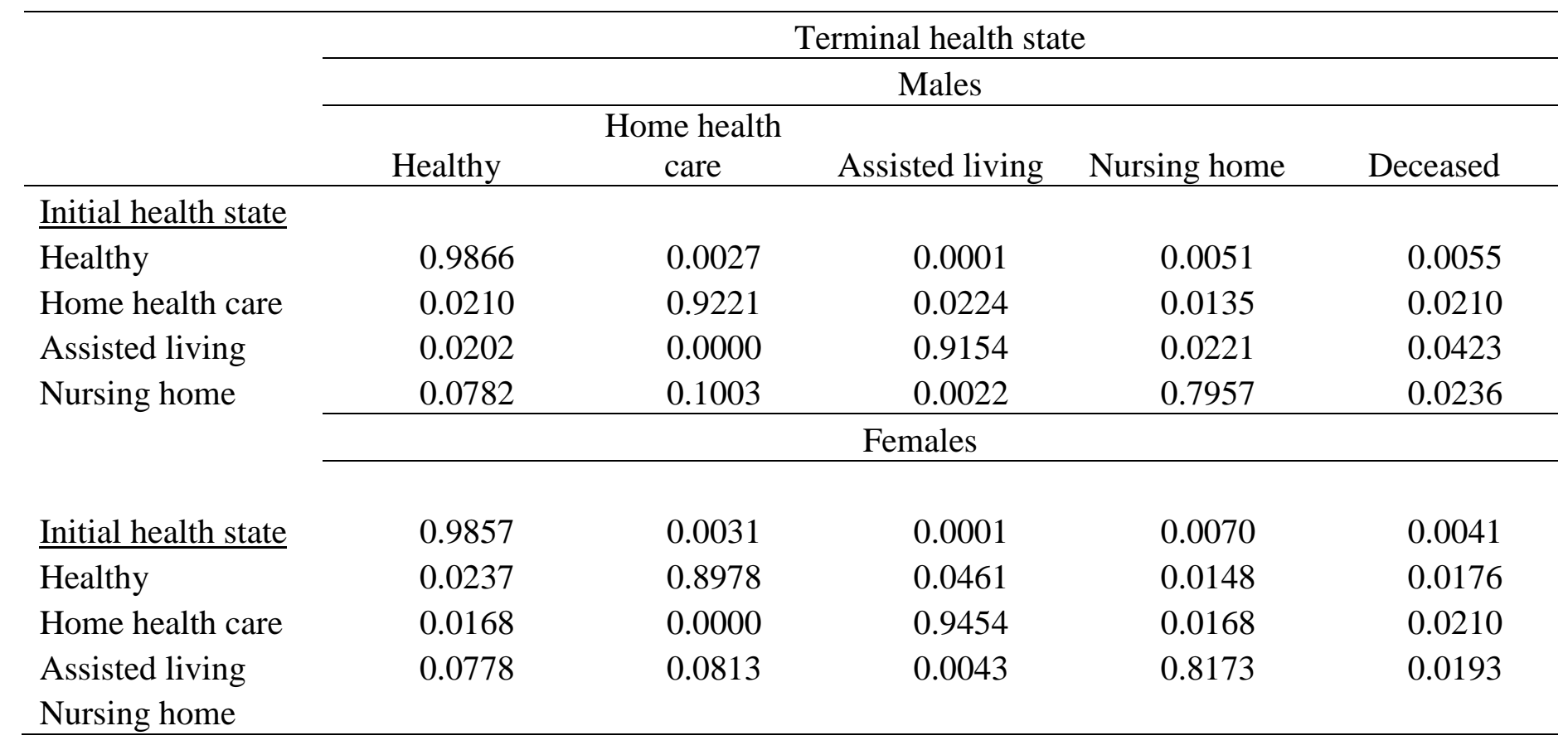

Notes: Authors’ calculations. 


\section{Appendix}

\section{Definition of disability using $A D L$ information}

The NLTCS asks detailed questions about cognitive and physical impairment. Robinson categorizes an individual as suffering from a cognitive impairment if he is unable to provide correct answers to five or more out of a total of ten questions that are designed to measure cognitive functioning. The ADLs comprise eating, bathing, dressing, toileting, being able to get out of bed, and bowel and bladder management. Determining the prevalence of ADL limitations involves determining thresholds for disability, and also deciding how to assign disability rates to those who are screened out in later sub-sampling. Previous authors have taken various approaches, which we compare in the Appendix. Stallard and Yee (1999) and Stallard (2011) presents a seven-tier ordering of limitation for each ADL, ranging from being able to perform the ADL independently, through using special equipment, standby and active help, to being unable to perform the ADL. They also give users of their classification system (insurers or researchers, for example) the option to impose a requirement that individuals require assistance all or most of the time, as opposed to occasionally or some of the time. In contrast, Robinson and Manton, Gu, and Lamb (2006) simply classify individuals as disabled or non-disabled, each relying on slightly different questions.

As shown in Appendix Table 1A, Manton, Gu, and Lamb report substantial declines in ADL limitations and institutionalization rates over the period 1982-2004 using the NLTCS, which we will account for by including a time trend. In contrast, when we apply the Robinson ADL definitions but retain the Manton, Gu, and Lamb sample weights, we find much smaller percentages with multiple ADL limitations and much larger percentages with IADL limitations (Appendix Table 1B). Appendix Tables 2A and 2B cross-tabulate ADL counts based on the two definitions. In both years, a substantial number of individuals lie in the upper right triangle, having more ADLs under the Manton, Gu, and Lamb than the Robinson definition.

To delve further, in Appendix Table 3 we compare the coding of the eating ADL of individuals resident in the community that was adopted by the authors of the above papers with the categorization adopted by Stallard and Yee (1999). ${ }^{43}$ The difference in the incidence of the eating ADL limitation between Robinson and Manton, $\mathrm{Gu}$, and Lamb reflects the omission by Robinson of the following types of individuals from the definition of those who are impaired: 1)

\footnotetext{
${ }^{43} \mathrm{Jim}$ Robinson notified us of his coding in correspondence. The Manton, Gu, and Lamb (2006) coding is reported on the NLTCS website.
} 
those who are unable to perform the activity, 2) those who are unable to perform the activity only some of the time or occasionally, 3) those for whom the Robinson definition of disability is stricter because Robinson requires that individuals get help with feeding, cutting meat, or buttering bread, and 4) those identified in follow-up questions as needing stand-by help. ${ }^{44}$ The coding of other ADL limitations follows a similar pattern.

With regard to ADLs, our evaluation is that the Manton, Gu, and Lamb classification provides a clearer overall distinction between the disabled and the disability-free because it includes those who merely need special equipment and those who need care part of the time. But, it is perhaps less well suited for our purposes because some of those classified as disabled, for example those only requiring special equipment or stand-by assistance, would be unlikely to qualify for long-term care insurance benefits (Cohen, Gordon, and Miller, 2011). However, the exclusion by Robinson of those unable to perform the activity seems incorrect. We therefore adopt the Robinson classification, except we reclassify those unable to perform the activity as disabled.

With regard to other limitations, Manton, Gu and Lamb classify people as having an IADL limitation if they report a limitation that is "significant”. ${ }^{45}$ Robinson classifies people as having an IADL limitation if they report any limitation at all. The Robinson approach yields an implausibly large and increasing percentage of the population as subject to an IADL limitation. We therefore adopt the Manton, Gu and Lamb classification of IADL limitations.

After settling on a definition of IADL and ADL limitations, we follow Robinson in defining states of progressively greater impairment: well (no cognitive impairment and able to perform all ADLs and IADLs, unable to perform 1+ IADL but able to perform ADLs; no cognitive impairment but unable to perform 1, 2, or 3+ ADLs; or cognitive impairment and unable to perform $<2$ or $2+$ ADLs. Table 7A reports the percentages of NLTCS participants in each of these seven impairment states, by age group, in 1984 and 2004, using our preferred definitions. Consistent with previous research, age-specific disability rates declined over the

\footnotetext{
${ }^{44}$ To illustrate, an individual who reported that they did not need help eating but who reported using special utensils or dishes would be classified by Manton, Gu, and Lamb (2006) as disabled but would be classified by Robinson (1996) as disability-free. An individual who reported that he needed help eating but who reported that he fed himself and did not receive help cutting meat or buttering bread would likewise be classified as disabled by Manton, $\mathrm{Gu}$, and Lamb (2006), but not by Robinson (1996). A table setting out the impact of the above differences in classification on the incidence of each ADL is available on request.

${ }^{45}$ IADLs include being able to prepare meals, do laundry, shop for groceries, take medicines, or make phone calls without help, manage money, and do light housework.
} 
above period. For example, the share of the sample who are well (no IADLs or ADLs) is $54.2 \%$ for men aged 85-89 in 1984 and 65.4\% in 2004.

Definition of Home Health Care and Assisted Living Use

The NLTCS questions on housing status have changed over time. In 2004, the screener questionnaire asks individuals whether they are living in 1) regular housing, 2) an ALC, CCRC, or Congregate Care Facility (CCF), 3) a nursing wing of a CCRC, or 4) a unit in a nursing, convalescent or rest home, or home for the aged. We follow the NLTCS protocol and categorize all residents of CCRCs as living in assisted living facilities, regardless of whether they are receiving nursing care. In 1999 and previous waves, the survey first identifies whether individuals are living in a nursing home, and then asks the non-institutionalized, “...if this place is part of a building or community intended for older or retired, or disabled persons?” It is not therefore possible to distinguish between ILCs, ALRs, CCRCs and CCFs. For 1999 and previous wave, we follow Robinson (1996) and categorize all accommodation intended for older persons as assisted living facilities. This will likely bias upwards estimates of the utilization of assisted living facilities. The NLTCS asks detailed questions about home health care, including the types of care provided, the frequency of provision, whether it was provided by family members or by paid caregivers, and the amount spent on care. 
Appendix Table 1A. ADL Limitations by Year - Manton, Gu, and Lamb Definition

\begin{tabular}{lcccccc}
\hline & 1982 & 1984 & 1989 & 1994 & 1999 & 2004 \\
\hline Nondisabled & $73.6 \%$ & $73.8 \%$ & $75.2 \%$ & $76.9 \%$ & $78.8 \%$ & $81.0 \%$ \\
IADL only & 5.7 & 6.0 & 4.5 & 4.4 & 3.3 & 2.4 \\
$\begin{array}{l}\text { One or two } \\
\text { ADL }\end{array}$ & 6.8 & 6.9 & 6.6 & 6.1 & 6.3 & 5.6 \\
$\begin{array}{l}\text { Three or four } \\
\text { ADL }\end{array}$ & 2.9 & 3.0 & 3.7 & 3.4 & 3.7 & 3.8 \\
Five or six & & & & & & \\
ADL & 3.5 & 3.3 & 3.1 & 2.9 & 3.0 & 3.2 \\
Institution & 7.5 & 7.0 & 6.9 & 6.3 & 4.9 & 4.0 \\
\hline
\end{tabular}

Note: PNAS weights.

Appendix Table 1B. ADL Limitations by Year - Robinson Definition

\begin{tabular}{lcccccc}
\hline & 1982 & 1984 & 1989 & 1994 & 1999 & 2004 \\
\hline Nondisabled & $72.0 \%$ & $70.4 \%$ & $70.4 \%$ & $65.9 \%$ & $66.8 \%$ & $66.8 \%$ \\
IADL only & 12.6 & 17.8 & 17.5 & 19.4 & 20.9 & 22.0 \\
One or two ADL & 6.3 & 3.5 & 3.6 & 6.8 & 6.0 & 5.6 \\
Three or four & & & & & & \\
ADL & 1.2 & 1.0 & 1.3 & 1.2 & 1.0 & 1.1 \\
Five or six ADL & 0.4 & 0.3 & 0.3 & 0.4 & 0.4 & 0.5 \\
Institution & 7.5 & 7.0 & 6.9 & 6.3 & 4.9 & 4.0 \\
\hline
\end{tabular}

Note: PNAS weights. 
Appendix Table 2A. ADL Count Using Alternative Definitions - 1982

\begin{tabular}{|c|c|c|c|c|c|c|c|c|}
\hline \multicolumn{9}{|c|}{ Manton, Gu, and Lamb } \\
\hline & 0 & 1 & 2 & 3 & 4 & 5 & 6 & Total \\
\hline 0 & 16,294 & 879 & 464 & 268 & 126 & 68 & 84 & 18,183 \\
\hline 1 & 368 & 316 & 256 & 166 & 143 & 107 & 123 & 1,479 \\
\hline 2 & 0 & 25 & 35 & 41 & 63 & 106 & 106 & 376 \\
\hline 3 & 0 & 0 & 3 & 10 & 30 & 65 & 104 & 212 \\
\hline 4 & 0 & 0 & 0 & 1 & 2 & 46 & 88 & 137 \\
\hline 5 & 0 & 0 & 0 & 0 & 1 & 13 & 61 & 75 \\
\hline 6 & 0 & 0 & 0 & 0 & 0 & 0 & 23 & 23 \\
\hline Total & 16,662 & 1220 & 758 & 486 & 365 & 405 & 589 & 20,485 \\
\hline
\end{tabular}

Note: Authors' calculations.

Appendix Table 2B. ADL Count Using Alternative Definitions - 2004

\begin{tabular}{|c|c|c|c|c|c|c|c|c|}
\hline \multicolumn{9}{|c|}{ Manton, Gu, and Lamb } \\
\hline ADL counts using Robinson's definition & 0 & 1 & 2 & 3 & 4 & 5 & 6 & Total \\
\hline 0 & 16,591 & 540 & 379 & 272 & 141 & 41 & 56 & 18,020 \\
\hline 1 & 177 & 159 & 153 & 146 & 129 & 67 & 62 & 893 \\
\hline 2 & 0 & 6 & 19 & 28 & 48 & 63 & 58 & 222 \\
\hline 3 & 0 & 0 & 1 & 5 & 8 & 52 & 75 & 141 \\
\hline 4 & 0 & 0 & 0 & 0 & 2 & 24 & 87 & 113 \\
\hline 5 & 0 & 0 & 0 & 0 & 0 & 5 & 66 & 71 \\
\hline 6 & 0 & 0 & 0 & 0 & 0 & 1 & 43 & 44 \\
\hline Total & 16,768 & 705 & 552 & 451 & 328 & 253 & 447 & 19,504 \\
\hline
\end{tabular}


Notes: Authors' tabulations. Non-institutionalized individuals only.

Appendix Table 3. Comparison of Codings of Eating ADL

\begin{tabular}{|c|c|c|c|c|c|c|}
\hline \multirow{2}{*}{$\begin{array}{c}\text { Stallard } \\
\text { disability } \\
\text { ranking }\end{array}$} & \multicolumn{2}{|l|}{ Stallard } & \multicolumn{2}{|c|}{ Manton, Gu, and Lamb } & \multicolumn{2}{|c|}{ Robinson } \\
\hline & Classification & Coding & Classification & Coding & Classification & Coding \\
\hline 0 & Performs the ADL independently & $1 a=2,1 b=2$ & No & & No & \\
\hline 1 & $\begin{array}{l}\text { Needs help, but does not get help, with } \\
\text { the ADL }\end{array}$ & $1 a=2,1 b=2$ & No & 当 & No & $\overparen{乛}$ \\
\hline 2 & $\begin{array}{l}\text { Performs the ADL with special } \\
\text { equipment }\end{array}$ & $1 a=2,1 b=1$ & Yes & 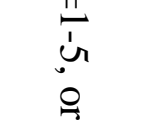 & Yes & 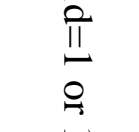 \\
\hline 3 & Gets standby help, no equipment & $\begin{array}{c}1 a=2,1 b=2, \\
7 b=1\end{array}$ & No & : & No & 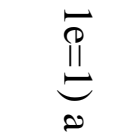 \\
\hline 4 & $\begin{array}{l}\text { Gets standby help, also uses special } \\
\text { equipment }\end{array}$ & $\begin{array}{c}1 \mathrm{a}=2,1 \mathrm{~b}=1, \\
1 \mathrm{c}=1\end{array}$ & Yes & $\begin{array}{l}\infty \\
\wp \\
\infty\end{array}$ & Yes & 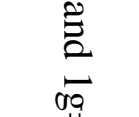 \\
\hline 5 & Gets active help, no equipment & $1 a=1,1 b=2$ & Yes & $\stackrel{\circ}{\stackrel{0}{I I}}$ & Yes & $\stackrel{11}{\models}$ \\
\hline 6 & $\begin{array}{l}\text { Gets active help, also uses special } \\
\text { equipment }\end{array}$ & $1 \mathrm{a}=1,1 \mathrm{f}=1$ & Yes & & Yes & \\
\hline 7 & Unable to perform the ADL. & $1 a=3$ & Yes & & No & \\
\hline
\end{tabular}

Note: Authors' analysis of NLTCS codebook, Stallard and Yee (1999), and documents provided by Eric Stallard and Xilaing Gu. 


\section{RECENT WORKING PAPERS FROM THE CENTER FOR RETIREMENT RESEARCH AT BOSTON COLLEGE}

SSI at 62: Protecting the Vulnerable When Increasing Social Security's Early Entitlement Age

Norma B. Coe and April Yanyuan Wu, June 2014

Why Do SSI and SNAP Enrollments Rise in Good Economic Times and Bad?

Matthew S. Rutledge and April Yanyuan Wu, June 2014

The Impact of Mandatory Coverage on State and Local Budgets

Alicia H. Munnell, Jean-Pierre Aubry, and Anek Belbase, May 2014

Interest Rates and Economic Growth: Are They Related?

Barry P. Bosworth, May 2014

The Tradeoff Between Health and Wealth in Retirement Decisions

Kristine M. Brown, May 2014

The Effect of Increasing Earnings Dispersion on Social Security Payroll Tax Receipts

Richard Kopcke, Zhenyu Li, and Anthony Webb, May 2014

What Impact Does Social Security Have on the Use of Public Assistance Programs Among the Elderly?

Norma B. Coe and April Yanyuan Wu, May 2014

Differential Mortality and Retirement Benefits in the Health and Retirement Study Barry P. Bosworth and Kathleen Burke, April 2014

Adding Employer Contributions to Health Insurance To Social Security's Earnings and Tax Base

Karen E. Smith and Eric Toder, April 2014

Lower-Income Individuals Without Pensions: Who Misses Out and Why?

April Yanyuan Wu and Matthew S. Rutledge, March 2014

How Do Subjective Longevity Expectations Influence Retirement Plans?

Mashfiqur R. Khan, Matthew S. Rutledge, and April Yanyuan Wu, January 2014

Impact of the Great Recession on Retirement Trends in Industrialized Countries

Gary Burtless and Barry P. Bosworth, December 2013

All working papers are available on the Center for Retirement Research website (http://crr.bc.edu) and can be requested by e-mail (crr@bc.edu) or phone (617-552-1762). 